\title{
Medidas de la Administración Tributaria de Chile y los efectos en la tributación internacional debido a la crisis por el covid-19
}

\author{
Measures of the Chilean Tax \\ Administration and the effects on \\ international taxation due to the \\ covid-19 crisis
}

\section{Medidas da Administração Tributária Chilena e os efeitos na tributação internacional devido à crise do covid-19}

AUTORES VARIOS*

\footnotetext{
Evelyn Arancibia Fredes, magíster en Planificación y Gestión Tributaria de la Universidad de Santiago de Chile. Abogada del Servicio de Impuestos Internos (sII) Chile. Miembro Grupo de Investigación Conocimientos Tributarios Latam. arancibia.evelyn@gmail.com / https://orcid.org/0000-0002-1809706. Marcos Bravo Catalán, magíster en Planificación y Gestión Tributaria de la Universidad de Santiago de Chile. Socio Beps Consultores. Miembro Grupo de Investigación Conocimientos Tributarios Latam. marcos.bravo@beps. cl / https://orcid.org/0000-0002-2339-7173. Gonzalo Garrido Pavez, LLM Pontificia Universidad Católica de Chile. Abogado del Servicio de Impuestos Internos (sII) de Chile. Miembro Grupo de Investigación Conocimientos Tributarios Latam. gonzalo.garrido.p@gmail.com / https://orcid.org/00000002-9953-7582. Alejandro Leiva Villegas, magíster en Tributación de la Universidad de Chile. Abogado de La Espiga Consultores Tributarios SpA. Miembro Grupo de Investigación Conocimientos Tributarios Latam. aleiva. villegas@gmail.com / https://orcid.org/0000-0002-7131-5988; Isaías Mora Rubio, diplomado en Tributación de la Universidad de Chile. Coordinador del Centro de Estudios Tributarios de la Universidad de Chile (СЕT). Miembro Grupo de Investigación Conocimientos Tributarios Latam. imora@fen. uchile.cl / https://orcid.org/0000-0003-3718-2189 Dor: https://doi.org/10.18601/16926722.n18.03
} 


\section{Resumen}

El primer caso de covid-19 en Chile fue reportado el día 3 de marzo del presente año. El 18 del mismo mes, el Gobierno publicó en el Diario Oficial el Decreto Supremo 104, que declara el estado de catástrofe en todo el territorio nacional por 90 días. Desde entonces, se han anunciado y puesto en práctica una serie de medidas de índole sanitaria y económica para controlar o aminorar los efectos que esta crisis ha tenido en el país. En el ámbito económico, un papel fundamental lo han tenido las medidas tributarias, las cuales buscan, en general, aliviar la carga tributaria de los contribuyentes, para darles una mayor liquidez de recursos y, de esa manera, evitar el despido de personal o incluso el cierre de empresas.

En el presente artículo se describen someramente las medidas tributarias tomadas por el Gobierno con los objetivos señalados. Debido a que la crisis se encuentra aún en desarrollo, esta no pretende ser una muestra definitiva de todas las herramientas que podrían ser utilizadas, sino solo de aquellas que fueron anunciadas e implementadas en primer lugar.

Palabras clave: caducidad; cobro; covid 19; devoluciones; fiscalización; impuestos; informes; prescripción; servicios digitales; precios de transferencia.

\section{Abstract}

The first COvID-19 in Chile was reported on March 3rd, 2020. On March $18^{\text {th }}$, the Government published on the official journal the Decree number 104, that declares the Constitutional State of Disaster Emergency throughout the whole of Chile for ninety days. Since then, several sanitary and economic measures have been announced, to stop or mitigate the effects of this crisis. In the economic area, tax policies have taken an important place. These measures seek to give a tax relief, to give Companies liquidity and capital resources and, in this way, avoid mass dismissals or the closure of companies.

This article summary describes tax measures taken by the Chilean government to reach above mentioned objectives. Due to this epidemy is an ongoing crisis, this work does not pretend to be a definitive list of tools that can be taken, but only shows examples of those which were announced in the first place.

Key words: Expiry; collection; Covid 19; returns; audit; taxes; reports; prescription; digital services; transfer pricing. 


\section{Resumo}

O primeiro caso de Covid-19 no Chile foi relatado em 3 de março deste ano. No dia 18 do mesmo mês, o governo publicou o Decreto Supremo número 104 no jornal oficial, que declara estado de catástrofe em todo o território nacional por 90 dias. Desde então, uma série de medidas econômicas e de saúde foram anunciadas e implementadas para controlar ou diminuir os efeitos dessa crise no país. Na esfera econômica, um papel fundamental tem sido desempenhado pelas medidas tributárias, que geralmente buscam aliviar a carga tributária dos contribuintes, dar-lhes maior liquidez de recursos e, assim, evitar a demissão de pessoal ou mesmo fechando.

Este artigo descreve brevemente as medidas tributárias adotadas pelo Governo com os objetivos declarados. Como a crise ainda está em desenvolvimento, isso não pretende ser uma amostra definitiva de todas as ferramentas que poderiam ser usadas, mas apenas daquelas que foram anunciadas e implementadas em primeiro lugar.

Palavras-chave: Caducidade; coleção; covid 19; devolução; auditoria; impostos; relatórios; prescrição; serviços digitais; preços de transferência.

\section{Introducción}

El escenario económico para Chile durante el año 2020 es crítico de acuerdo con el Plan Económico de Emergencia del Gobierno, anunciado en marzo de 2020, y que busca proteger la salud, los ingresos y el trabajo. Y es que los efectos del covid-19 han llevado a un fuerte ajuste de las perspectivas de crecimiento, no solo en Chile, sino a nivel global. Las monedas de países emergentes como las latinoamericanas se han depreciado frente al dólar, producto de la disminución de los precios de los commodities (el cobre, por ejemplo, principal producto de exportación chileno) y a la salida de capitales.

En este contexto, el presente escrito da cuenta del impacto de la pandemia en Chile y de las medidas tomadas por el Gobierno desde el escenario tributario para afrontar la crisis. Es importante tener presente que el artículo da cuenta de forma estricta de la regulación expedida.

\section{Los efectos de la pandemia en el crecimiento de la economía chilena}

El golpe de la pandemia a la economía chilena no pudo llegar en peor momento, pues la situación interna no era la mejor, producto de la crisis social que comenzó en octubre de 2019. El Ejecutivo estima una caída de 2,0\% del producto interno bruto (PIB). Las perspectivas plantean una baja actividad económica (-14,1\% en abril 2020) (figura 1) y se estima que la demanda interna caerá este año un 3,3\%, debido a la contracción del consumo privado, entre otros factores. 
Figura 1. Indicador mensual de actividad económica (en porcentaje, Base $2013=100$ )

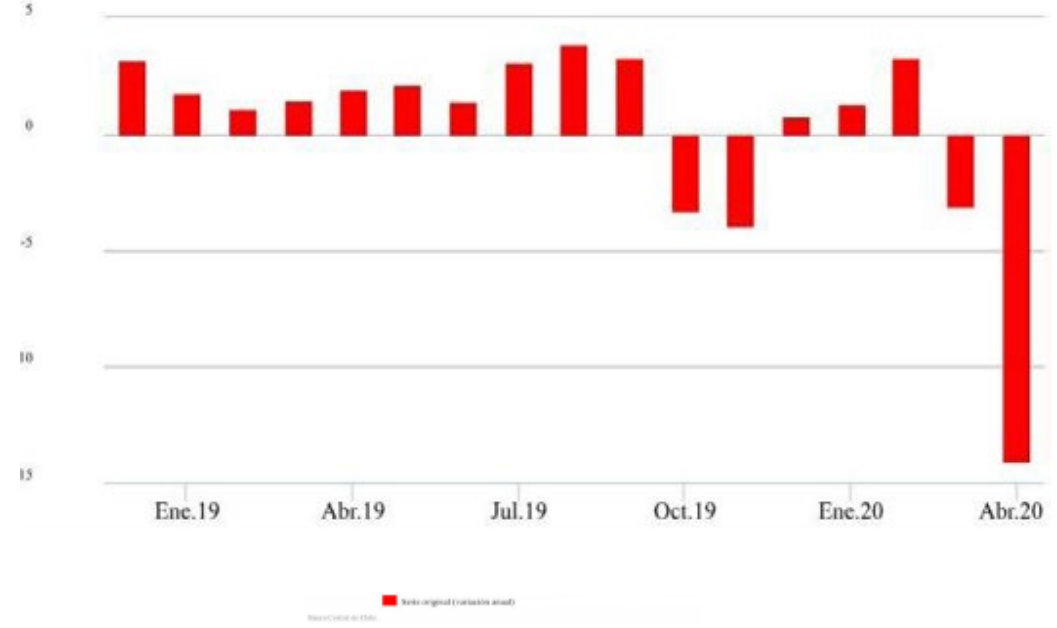

Fuente: Banco Central de Chile (2013).

Las medidas de confinamiento decretadas para enfrentar la pandemia del coronavirus en Chile afectaron negativamente la actividad económica y, en consecuencia, según señaló la Dirección de Presupuesto (DIPRES) del Ministerio de Hacienda, las arcas fiscales disminuyeron $35,8 \%$ en abril de 2020 respecto a igual periodo de 2019 , los principales factores de esto fueron el adelanto en la devolución de impuestos de la Operación Renta 2020, la menor actividad económica (contracción de 14,1\% en abril de 2020) y las medidas del Plan Económico de Emergencia, con postergación por tres meses del pago de impuesto al valor agregado (IVA) y pagos provisionales mensuales (PPM), para empresas con ventas menores a 350.000 unidades de fomento (UF), pudiendo pagar en 6 o 12 cuotas sin multas ni intereses, con un costo fiscal estimado de US\$1.500 millones. La recaudación por IVA, que es prácticamente la mitad del total de ingresos tributarios netos, cayó 8,6\% tras la crisis social de octubre de 2019, mientras que en abril de 2020 cayó un 6,2\% real respecto del mismo periodo del año anterior.

La Corporación Nacional del Cobre (CODELCO), en su actividad minera, aportó 85,5\% menos de excedentes al Estado de Chile, US\$54 millones de excedentes en el primer trimestre de 2020 contra US\$372 millones en mismo periodo de 2019 , por la pronunciada caída en el precio del cobre (US\$2,49 la libra promedio en el primer trimestre de 2020 contra US\$2,72 en el mismo periodo de 2019), la menor venta y una mayor amortización de desarrollo minero, a raíz de los efectos económicos derivados de la crisis sanitaria.

También se afectó negativamente el mercado laboral, tal como indica la tasa de desempleo, en marzo de 2020 fue de $15,6 \%$ (equivale a 469.284 personas desocupadas en el Gran Santiago), la cual se ubica sobre el promedio de los últimos 20 años $(9,5 \%)$ (en la figura 2 es el "Promedio serie"), y sobre el promedio de los últimos 10 años $(7,6 \%)$. La evolución del desempleo se explica principalmente por los efectos de la pandemia 
mundial en la economía nacional que han generado destrucción neta de empleo en las ramas de actividades económicas.

Figura 2. Tasa de desempleo en el Gran Santiago (porcentaje)

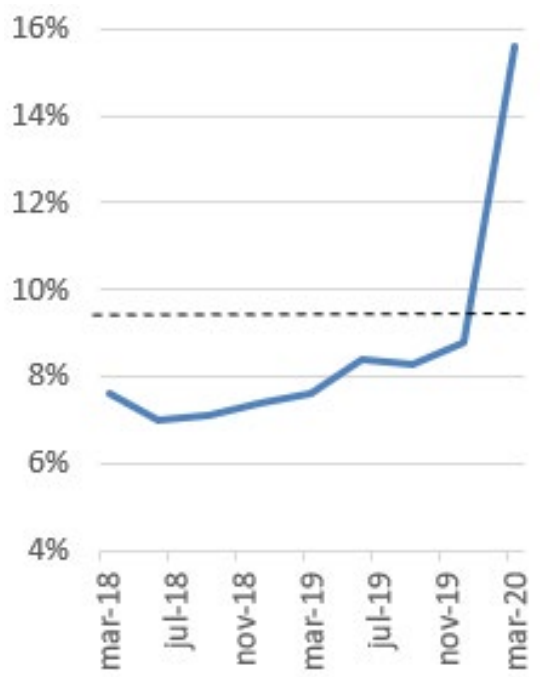

Fuente: Centro de Microdatos, Universidad de Chile (2020).

El Ministerio de Economía, a través del Instituto Nacional de Estadísticas (INE), estimó para el trimestre febrero-abril de 2020 que la tasa de desocupación nacional fue 9,0\% (figura 3 ), con un incremento de 1,9 puntos porcentuales en doce meses.

Figura 3. TASA de desempleo nacional (PORCENTAJe)

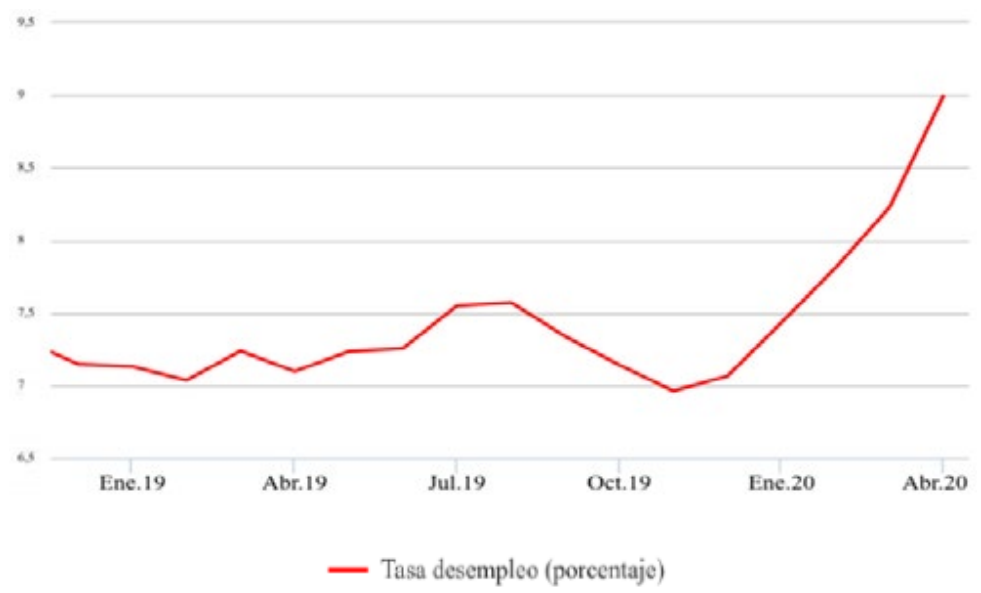

Fuente: Instituto Nacional de Estadísticas (2020). 
Por su parte, el Fondo Monetario Internacional (FMI) estima una contracción global de la economía en 3,0\% durante 2020 y, a su vez, prevé un rebote expansivo de 5,8\% en 2021. También, señala que la actividad económica en la región de América Latina y el Caribe se reducirá en 5,2\% este año, mientras que para 2021 se estima una recuperación parcial de 3,4\%. Además, el FMI pronostica que la economía de Chile se contraerá un 4,5\%; México un 6,6\%; Argentina un 5,7\%; Brasil un 5,3\%; Perú un 4,5\%; Bolivia un 2,9\% y Colombia un 2,4\%. La restauración económica en 2021, según estimaciones del FMI, será liderada por Chile con un aumento del 5,3\% del PIB; Perú con 5,2\%; Argentina con 4,4\%; México con $3 \%$ y Brasil con 2,9\%.

Entonces, el panorama no es el mejor para América Latina, y es importante tener presente que, en términos económicos, las interrelaciones comerciales entre vecinos generan una suerte común, para bien o para mal, y hoy se observa efecto dominó en la región, que plantea el reto de trabajo común entre los Estados.

\section{La administración tributaria frente al covid-19 en Chile}

Las medidas de cuarentena y confinamiento complicaron los procesos de fiscalización, máxime si el Servicio de Impuestos Internos (sI o autoridad tributaria) no cuenta con los procesos virtuales avanzados para viabilizar las actuaciones de la administración de manera digital. Por otro lado, también se observa que los contribuyentes tampoco tienen un soporte tecnológico para responder a los requerimientos de la administración de manera digital. Hoy los contribuyentes continúan en su mayoría utilizando el soporte en papel de su documentación de respaldo, que guardan contratando sistemas de almacenaje externo, por lo que en una situación de cuarentena o confinamiento se obstaculiza el acceso fluido a esos antecedentes.

En este contexto se dificulta la fiscalización, lo que puede llevar fácilmente a dos extremos: que se prescriban impuestos o se cumplan los plazos de caducidad o que, por evitar esa situación que acarrea responsabilidad administrativa, los funcionarios emitan actuaciones sin contar con todos los antecedentes incurriendo en errores, lo que puede perjudicar la propia fiscalización e impedir a los contribuyentes que puedan defenderse de manera adecuada.

Así las cosas, ante esta situación tan excepcional, algunos Estados han optado por suspender los plazos de prescripción y de caducidad ${ }^{1}$. En Chile, esa iniciativa no ha nacido del Gobierno, sino de la Cámara de Diputados impulsada específicamente por el gremio de funcionarios de la Administración Tributaria² .

1 A nivel comparado es algo que se recoge, por ejemplo, en el caso de España (mediante Real Decreto 8 de 2020); prescripción y caducidad, Ecuador; prescripción y caducidad, en materias aduaneras. 


\section{A. Plazos de prescripción y caducidad en Chile}

En este país opera un sistema de autodeclaración, es decir, es el contribuyente quien debe determinar sus impuestos e informarlo a la Administración Tributaria o sII, estas declaraciones se encuentran sujetas a plazos de prescripción y de caducidad.

Con relación a los plazos de prescripción existe una denominada prescripción ordinaria o normal, que considera 3 años contados desde la expiración del plazo legal en que debió haberse efectuado la declaración, para que la Administración Tributaria pueda revisar, liquidar o girar impuestos y, por otro lado, la prescripción extraordinaria o ampliada, que dispone un término de 6 años en caso de declaraciones maliciosamente falsas o incompletas o cuando no hubiese existido declaración.

Además, existen prescripciones para sanciones pecuniarias que no acceden al pago de impuestos de 3 años y prescripciones por delito tributario ${ }^{3}$ cuyos plazos van de 5 años para delitos simples y de 10 años para crímenes.

Por otro lado, el órgano de la Administración del Estado encargado de fiscalizar los impuestos asociados al comercio exterior y las operaciones de importación y exportación es el Servicio Nacional de Aduanas. Los plazos de prescripción relevantes en materia aduanera corresponden a 3 años como regla general y 5 años en el caso de responsabilidad de funcionarios y empleados del Servicio de Aduanas, esta última prescripción aplica a simples infracciones y a delitos (fraude aduanero o contrabando).

Ahora bien, en el contexto de plazos de caducidad, que corresponde al máximo tiempo que tiene el sir para mantener abierto un proceso de fiscalización o para ejercer una acción de cobro desde que este inicia podemos hacer las siguientes precisiones:

- La regla general corresponde a 9 meses, desde que el contribuyente acompañó toda la información requerida por el Servicio. Este plazo aumentará a 12 meses cuando el proceso de fiscalización trate sobre: i) precios de transferencia; ii) determinación de renta líquida imponible de contribuyentes con ventas o ingresos superiores a 5.000 unidades tributarias; iii) cuando se revisen los efectos tributarios de procesos de reorganización empresarial; iv) cuando se revise la contabilización de operaciones entre empresas relacionadas.

- El plazo de caducidad será de 18 meses ampliable a 24 meses, cuando se trate de:

1. Recopilación de antecedentes: procedimiento que efectúa el Servicio para reunir antecedentes y decidir si ejercer la acción penal (en Chile, la administración tributaria tiene la exclusividad del ejercicio de la acción penal, es decir, solo el sir puede 
interponer denuncia o querella, nadie más puede hacerlo, por tanto, tampoco el Ministerio Público ${ }^{4}$ ).

2. En caso de aplicación de la Norma General Antielusiva.

3. En caso de aplicación de la norma sobre Controlled Foreign Companies.

Cabe señalar que, una vez se haya efectuado un proceso de fiscalización, no podrá volver a abrirse otro en periodos posteriores, por los mismos hechos, a menos que se trate de impuestos distintos.

En el caso del Servicio Nacional de Aduanas, los plazos van de 2 años como regla general para emitir cargos por diferencias en aranceles y otros conceptos, y 5 años en el caso de dolo y documentación maliciosamente falsa.

Ahora bien, para la fecha de redacción de artículo, debido a la situación excepcional del covid-19, que impide que la Administración Tributaria desarrolle de forma normal los procedimientos de fiscalización, asunto que impactará en arcas fiscales, un grupo de diputados presentó un proyecto de ley ${ }^{5}$ que tiene como objetivo la suspensión de los plazos de prescripción y caducidad, inspirándose para ello en el Real Decreto español 8 de 2020.

Cabe señalar que los plazos que se suspenderían de acuerdo con este proyecto de ley son los del Código Tributario y de la Ordenanza de Aduanas, quedando fuera de esta suspensión los plazos de prescripción de delitos tributarios.

\section{B. Devoluciones}

Como se indicó, las medidas impulsadas por el Gobierno para contener la propagación del covid-19 están provocando importantes trastornos en los procesos y operativos de distribución de empresas. Las restricciones a la movilidad, los retrasos en la cadena de suministro, las drásticas reducciones en la demanda de los clientes impactan con gran virulencia en todos los sectores, sea cual sea su actividad.

4 Esto último se encuentra en discusión en Chile, pues no ha ejercido acción penal en algunos casos en que la opinión pública, e incluso el propio Ministerio Público, ha considerado que debió ejercerse. Se encuentra un proyecto de ley para cambiar esta situación y que dicho ejercicio no sea exclusivo.

5 La Asociación de Fiscalizadores elevó este tema ante los diputados. El Proyecto de Ley consta en el Boletín 13487-05, de 28 de abril de 2020, el cual consigna lo siguiente: “Artículo Único. Tratándose de los plazos de prescripción y caducidad establecidos para la liquidación, giro y fiscalización del impuesto, como asimismo, para el ejercicio de acciones previstas en el Código Tributario, en el D.L. 824 sobre impuesto a la renta, en el D.L 825 sobre impuesto a las ventas y servicios y en el Decreto con Fuerza de Ley $N^{\circ}$. 30 que fijo el texto refundido de la Ordenanza de Aduanas, se entenderán suspendidos desde la fecha de declaración del estado de excepción constitucional de catástrofe, por calamidad pública, en virtud del decreto supremo $\mathrm{N}^{\circ}$. 104, de 18 de marzo de 2020, del Ministerio del Interior y Seguridad Pública, y el tiempo en que este sea prorrogado, si es el caso". El proyecto ingresó a la Comisión de Hacienda de la Cámara de Diputados, con fecha 06 de mayo de 2020. Dado que el sistema chileno es hiperpresidencialista, solo él puede acelerar los procesos, si el Gobierno no pone urgencia o suma urgencia a los proyectos, no pueden verse con preferencia, lo que alarga los tiempos para despacharlos. Como este proyecto no fue enviado por el Gobierno, lo más probable es que no establezca urgencias. 
En este contex to, uno de los problemas más complejos que genera el confinamiento es la falta de liquidez para hacer frente a obligaciones y sobrellevarlo, es por eso que el Estado anunció una medida que involucra la devolución de impuestos de manera anticipada.

Esta política solo se refiere al impuesto a la renta y no aborda otras medidas que podrían incidir en dar mayor liquidez, como podría ser la obligación del Fisco de devolver tributos que son consecuencia de sumas que los contribuyentes hayan enterado en exceso, o en forma indebida o errónea y que se hubiese requerido su devolución, respecto a las cuales en Chile no existe un plazo determinado en las normas tributarias, sino que se aplica facultativamente el plazo de 6 meses contemplado en la Ley de Bases de Procedimiento Administrativo.

\section{Imposición sobre la renta}

En el contexto de esta investigación, damos cuenta que el día 1 de abril del año 2020, se dictó el Decreto Supremo 420 que estableció medidas tributarias para apoyar a las familias, trabajadores y empresas, para enfrentar las dificultades generadas por el covid-19. Las medidas concentradas en este Decreto apuntaban a incorporar políticas tributarias que otorgaran mayor liquidez.

En el ámbito de las devoluciones de impuesto, la información pública (sII, 2 de abril de 2020) da cuenta de que el primer día de declaración de las rentas obtenidas en el año comercial 2019 (Operación Renta 2020) generó un alto interés en los contribuyentes para realizarla, ya que existía una medida de apoyo ${ }^{6}$ que inyectaba liquidez a los trabajadores independientes ${ }^{7} \mathrm{y}$ al segmento de las micro, pequeñas y medianas empresas (Mipymes ${ }^{8}$ ).

Una de las medidas de apoyo indicadas consistió en anticipar la devolución del impuesto a la renta, de esta forma, para aquellos contribuyentes que declaran sus impuestos las primeras semanas del mes de abril, la devolución podía ser obtenida a partir del día 21 del mismo mes, situación que el año anterior había ocurrido en el mes mayo ${ }^{9}$.

6 En el contexto de las medidas de apoyo existían otras que tienen que ver con la facilitación por parte de la Administración Tributaria chilena para poner a disposición de los contribuyentes de manera remota toda la información y orientación que requieren para que puedan cumplir con el trámite desde sus propias casas. Véase apartado sobre apoyo informático y electrónico para los tramites en tiempos de aislamiento preventivo.

$7 \quad$ En Chile se entiende por trabajador independiente aquel que no tiene un contrato de trabajo con un empleador y se vincula a través de contratos de prestación de servicios, emitiendo la documentación tributaria de boleta de honorarios. En la boleta de honorarios, cuando aquel al que se le presta el servicio es un contribuyente que tributa bajo el régimen de renta efectiva con contabilidad completa, este deberá retener un porcentaje equivalente al 10,75\% a título de impuestos, el cual deberá enterarse en arcas fiscales.

8 En Chile este segmento está compuesto por las empresas que tienen ventas anuales hasta el monto de los 3,5 millones de dólares. El valor es aproximado dado que existe flotación cambiaria, pero se tomó el equivalente de 1 usD que es igual a 820 pesos chilenos.

El año 2019 estas devoluciones comenzaron a realizarse el día 13 de mayo. 
Además de lo indicado, en el segmento de los trabajadores independientes que emitieron boletas de honorarios electrónicas y a quienes les retuvieron impuestos, se les permitió recibir la devolución de sus retenciones correspondientes a enero y febrero del año 2020 de forma anticipada, es decir, no debieron esperar el año 2021 para obtenerlas. Para acceder a este último beneficio no se requería un trámite especial.

\section{Cobro de impuestos}

En este apartado se desarrollan distintas medidas que tienen por finalidad facilitar el cumplimiento tributario o bien ayudar a los contribuyentes en el desarrollo de su giro. A continuación se resumen las más importantes.

\section{A. Ejercicio del derecho a voto a través de medios tecnológicos en las sociedades comerciales}

Con fecha 18 de marzo de 2020 se permitió la utilización de medios tecnológicos ${ }^{10}$ para asegurar la participación y votación de los accionistas en las juntas de accionistas de sociedades anónimas abiertas y sociedades anónimas especiales sujetas a la supervisión de la Comisión para el Mercado Financiero (CMF), de los tenedores de bonos en las juntas de tenedores de bonos o de los aportantes en las asambleas de aportantes de fondos sujetos a la supervisión de la CMF.

Así, los accionistas, tenedores de bonos o aportantes, según corresponda, podrán participar y votar a distancia siempre y cuando los medios tecnológicos que se utilicen para dicho fin garanticen correctamente la identidad del participante y la simultaneidad o el secreto de su votación, según corresponda, en dichas juntas o asambleas.

\section{B. Condonación de intereses y multas, y postergación de pago de impuestos ${ }^{11}$}

El Estado chileno entregó facilidades de pago para impuestos fiscales y territoriales bajo la denominación de "Aplazamiento de términos para la revisión de informes", y además permitirá la condonación, total o parcial, de intereses y multas para los contribuyentes que cumplan con determinados requisitos ${ }^{12}$ respecto del impuesto a la Renta, IVA y contribuciones, situación que rige hasta el 30 de septiembre de 2020.

10 La Comisión para el Mercado Financiero (CMF) emitió la Norma de Carácter General 435, que modificó la Norma de Carácter General 273 de 2010, que regula los sistemas de votación en la junta de accionistas.

11 A través del Decreto Supremo 420 de 2020, el Ministerio de Hacienda de Chile establece medidas tributarias para apoyar a las familias, trabajadores y a las micro, pequeñas y medianas empresas debido a las dificultades generadas por la covid-19.

12 Esta medida aplica para: i) contribuyentes de Impuesto Global Complementario o Impuesto Único de Segunda Categoría, cuyos ingresos anuales no excedan de 90 Unidades Tributarias Anuales, y ii) contribuyentes de 


\section{Medidas para apoyar a las familias y a las micro, pequeñas y medianas empresas por el covid-19 ${ }^{13}$}

En Chile, en un periodo de treinta años, la tasa de pobreza ha disminuido, sin embargo, muchos sectores de la población siguen privados de los beneficios del crecimiento económico. Esta privación se ha observado con bastante fuerza en este periodo de confinamiento, sobre todo en el caso de los trabajadores informales que, por temor a perder su medio de sustento, siguen trabajando incluso sin los cuidados, con la consiguiente exposición al coronavirus.

Además, consecuencia de la cuarentena y una política débil de protección de empleos y salarios, aumentó el nivel de desempleados en el país, lo que llevó a más personas a una situación de precariedad y pobreza, e hizo necesaria la intervención del Estado de la siguiente forma:

- Bono de Apoyo a los Ingresos Familiares para los beneficiarios de ciertos subsidios familiares.

- Capitalización extraordinaria del Banco del Estado.

- Reducción transitoria de la tasa del impuesto timbre y estampillas para operaciones crediticias celebradas entre abril y septiembre de 2020.

\section{A. Prohibición de pagar a empresas de menor tamaño en un plazo superior a 30 días $^{14}$}

Esta medida busca darle liquidez a las micro, pequeñas y medianas empresas, respecto al pago de los productos o servicios que vendan u ofrezcan. Así, se estableció una prohibición legal de celebrar "acuerdos con plazos de pago excepcional" (aquellos que permiten pactar plazos de pago superiores al legal), cuando la parte vendedora o prestadora del servicio (quien emite la factura) es una empresa de menor tamaño y la parte compradora o beneficiaria del servicio, no lo sea.

Sin embargo, estos acuerdos sí podrán realizarse cuando el plazo superior al legal se establezca en beneficio de la empresa de menor tamaño acreedora, y solo en aquellos casos que contemplen realización de pruebas, pagos anticipados, parcializados o por avances.

Impuesto de Primera Categoría cuyo ingreso anual no exceda de UF 350.000. En este último caso, también se consideran los ingresos de entidades relacionadas.

13 La Ley 21.225 de 2020 establece algunas medidas para apoyar a las familias y a las micro, pequeñas y medianas empresas por la covid-19.

14 Si bien esta ley no nace en época de covid-19, el apartado específico entró en vigor el día 3 de abril de 2020 , con la Ley 21.217 que modificó la Ley 19.983, que regula la transferencia y otorga mérito ejecutivo a copia de la factura. 
Además de lo anterior, se incluye un nuevo supuesto de "cláusula abusiva", señalando que no producirán efectos aquellas disposiciones que "Tengan por único objetivo retrasar el plazo de pago de la factura, estableciendo pagos parcializados", salvo en las operaciones en las que están involucradas empresas de menor tamaño.

\section{B. Gastos y donaciones efectuadas por contribuyentes para paliar los efectos del covid-19}

Con fecha 29 de abril de 2020, el sir emitió las instrucciones (Circular No 32, sil, 2020) que regulan el tratamiento tributario de los desembolsos incurridos a propósito de la emergencia sanitaria originada por el covid-19, y confirmó así el tratamiento de gasto tributario aceptado de los siguientes conceptos:

- Aquellas cantidades incurridas, voluntaria u obligatoriamente, por los contribuyentes y que se destinen a evitar, contener o disminuir la propagación del covid-19.

- Los desembolsos destinados a aminorar los efectos del covid-19 y que tengan por objeto, en general, resguardar los intereses del negocio del contribuyente, garantizando, por ejemplo: i) sus ingresos presentes o futuros; ii) la mantención o el apoyo a sus trabajadores, incluyendo pago de remuneraciones a pesar de no haber asistido al lugar de trabajo; iii) la realización de planes estratégicos de negocios y fidelización de clientes; y iv) evitar un mayor desembolso futuro o cualquier otro que se realice en interés o para el desarrollo o mantención del negocio.

- En virtud de lo anterior, se entienden aceptados como gasto: i) todos los desembolsos incurridos en la adquisición de bienes, tales como mascarillas, alcohol, gel, jabón líquido, dispositivos médicos, ropas o equipos especiales, entre otros, y ii) la contratación de servicios de sanitización o desinfección de instalaciones, entre otros. Estos bienes o servicios no se consideran incrementos de renta tributable para quienes los reciben.

- Adicionalmente, la instrucción se refiere al tratamiento tributario de ciertas donaciones realizadas al Fisco y a algunas instituciones determinadas, tales como personas naturales o jurídicas de derecho público, fundaciones o corporaciones de derecho privado, universidades reconocidas por el Estado y aquellas que Chile realice a un país extranjero.

\section{Política de convenios por el covid-19}

A través de su página web, la Tesorería General de la República ${ }^{15}$ informó de la expedición de una instrucción administrativa a fin de implementar una nueva política de convenios para el pago de impuestos y créditos fiscales morosos sujetos a cobranza.

15 En Chile, la institución encargada de determinar los impuestos adeudados es el Servicio de Impuestos Internos, en tanto que aquella que ejecuta los juicios de cobros es la Tesorería General de la República. 
Estos convenios van dirigidos a contribuyentes de impuesto global complementario e impuesto único de segunda categoría, cuyos ingresos anuales no excedan de 90 UTA, e impuesto de primera categoría, cuyo ingreso anual no exceda de UF 350.000.

Bajo el cumplimiento de ciertas condiciones, estos contribuyentes podrán suscribir un convenio de pago de hasta 24 cuotas.

Adicionalmente, respecto de aquellos contribuyentes que ya mantengan convenios vigentes con la Tesorería, se establece la posibilidad de postergar el pago de las cuotas de los meses de abril, mayo y junio de 2020, sin intereses ni multas. Estas cuotas podrán ser pagadas al final del convenio.

\section{Control, fiscalización y apoyo informático electrónico para los trámites en tiempos de aislamiento preventivo}

En el contexto del brote del covid-19, el sil ha buscado establecer políticas tendientes a fiscalizar de forma más eficiente y facilitar el cumplimiento de las obligaciones tributarias de los contribuyentes, disminuyendo la realización de trámites presenciales y facilitar las gestiones y los procedimientos administrativos.

En este aspecto, debemos dar cuenta de que, el sir ha sido un órgano pionero dentro de los organismos chilenos en cuanto a la "digitalización”, puesto que, desde hace ya varios años, viene implementando de manera gradual una plataforma informática que permita a los contribuyentes efectuar una serie de trámites de manera remota, sin la necesidad de acudir a las oficinas del Servicio.

Ya en el año 1992, el sII comenzó a desarrollar una estructura informática integrada que le permitiera contar con un sistema de validación "en línea” de las declaraciones de renta; a partir de esa implementación, se han dado una serie avances en esta materia a lo largo de los años, lo que permite que el sir hoy cuente con una serie de trámites "en línea" para la obtención de Rol Único Tributario (RUT), timbrar documentos tributarios, emitir facturas y boletas electrónicas, presentar declaraciones juradas, etc., contando además con aplicaciones para celulares para facilitar el acceso a sus plataformas y efectuar los trámites que se requieran.

Ahora bien, en casos de procedimientos de fiscalización y peticiones administrativas, la realidad era un poco diferente, puesto que tanto las presentaciones que el contribuyente hacía, como las aportaciones de documentos consecuencia de una fiscalización (al menos en el papel) por regla general se hacían de forma presencial.

Sucedía además que en esta época, la mayoría de los fiscalizadores aceptaban que los contribuyentes aportaran documentación por correo electrónico, una posibilidad que no estaba reglada ni tenía un reconocimiento legal expreso, dado que recién en el año 2014, con la expedición de la Ley 20.780, el Servicio impulsó la creación de un sistema de "expedientes electrónicos" que vinieron a ser la sistematización de una realidad que ya se estaba masificando en los grupos de fiscalización, lo que permite que el contribuyente 
presente su documentación tributaria subiéndola a su sitio personal, en un espacio designado al efecto.

Con la llegada de la pandemia, y la cuarentena en diversas comunas del país, el día 19 de marzo de 2020, el Servicio realizó un esfuerzo por sistematizar y presentar en una plataforma integrada el acceso a todos aquellos trámites que se pueden efectuar de manera remota. Junto con lo anterior, se anunció la posibilidad de autorizar, vía internet, los folios de boletas exentas y afectas en materia de IVA, así como la posibilidad de presentar documentación vía correo electrónico para realizar trámites relativos al Ciclo de Vida del contribuyente. La respuesta a dichas solicitudes también se entrega vía correo electrónico, con lo cual se genera un canal de comunicación que antes no era tan utilizado para los mencionados trámites.

Lo consignado en el párrafo anterior fue reforzado el día 19 de marzo del presente año por los canales de comunicación web del sir, donde se publicitaron los trámites en línea a través de la página web, con la finalidad de evitar aglomeraciones en las oficinas públicas y mantener sus labores de apoyo, control y fiscalización.

\section{A. Trámites en línea}

Actualmente, el si permite el desarrollo de una serie de gestiones que no requieren de trámites presenciales ante las oficinas de la autoridad tributaria. Estas pueden realizarse a través de la página web, mediante correo electrónico o directamente desde el teléfono móvil.

\section{Tabla 1. Trámites en línea}

\begin{tabular}{|c|c|}
\hline Canal de comunicación & Tipo de gestión \\
\hline \multirow{16}{*}{ Página web } & Obtención y recuperación de clave tributaria para acceder a página web. \\
\hline & Inscripción y obtención del RUT \\
\hline & Obtención de E RUT (cédula digital del RUT) \\
\hline & Iniciar actividades \\
\hline & $\begin{array}{l}\text { Actualizaciones de información del contribuyente: domicilio, sucursales, socios y } \\
\text { actividades económicas }\end{array}$ \\
\hline & Realizar peticiones administrativas \\
\hline & $\begin{array}{l}\text { Inscribirse en regímenes de tributación contemplados en la Ley sobre Impuesto a } \\
\text { la Renta (LIR) }\end{array}$ \\
\hline & Solicitud de certificados fiscales para presentar a entidades extranjeras \\
\hline & $\begin{array}{l}\text { Impugnar actos administrativos mediante la Reposición Administrativa Voluntaria } \\
\text { (RAV) y Recurso Jerárquico (RJ) }\end{array}$ \\
\hline & Verificación de documentos tributarios autorizados por el sII (timbraje) \\
\hline & Consultar situación tributaria de terceros \\
\hline & Consultar tasación de vehículos \\
\hline & Generar carpeta electrónica para instituciones financieras \\
\hline & Consultar avalúo fiscal y propiedad de bienes raíces \\
\hline & Autorización de boletas de ventas afectas a IVA \\
\hline & Emisión de documentos tributarios electrónicos (DTE) \\
\hline
\end{tabular}


Medidas de la Administración Tributaria de Chile y los efectos en la tributación internacional...

\begin{tabular}{|c|c|}
\hline Canal de comunicación & Tipo de gestión \\
\hline & Ingreso y generación de registro de compras y ventas para contribuyentes de IVA \\
\hline & Emisión de boleta de honorarios electrónica (вНЕ) \\
\hline & Envío de libros contables electrónicos \\
\hline & Declaración y rectificación de IVA (Formulario 29) \\
\hline & Declaración y rectificación de retenciones (Formulario 50) \\
\hline & Declaración y rectificación de impuesto anual a la renta (Formulario 22) \\
\hline & Declaración de impuesto a las herencias intestadas \\
\hline & Declarar el término de giro de las empresas \\
\hline & Pago de contribuciones \\
\hline \multirow{9}{*}{ Envío por correo electrónico } & Acreditación de domicilio \\
\hline & Modificación del tipo de contribuyente \\
\hline & Reorganizaciones empresariales \\
\hline & Informar inicio de actividades de personas jurídicas \\
\hline & Informar representantes de contribuyentes \\
\hline & Autorización de folios electrónicos para documentos tributarios \\
\hline & Modificaciones al capital de una entidad \\
\hline & Acreditaciones de actividad económica \\
\hline & Consultar sobre interpretación de la norma tributaria \\
\hline \multirow{7}{*}{ App } & Verificación de códigos de control fiscal \\
\hline & Propuesta de declaración de IVA \\
\hline & Emisión de facturas electrónicas \\
\hline & Reavalúo de bienes raíces no agrícolas \\
\hline & Obtención de E RUT \\
\hline & Declaración de renta de personas naturales \\
\hline & Emisión de boleta de honorarios electrónica \\
\hline
\end{tabular}

Fuente: elaboración propia.

\section{B. Expediente electrónico}

En el contexto ya descrito, el sil también señaló que todos los documentos o antecedentes que los contribuyentes deban presentar en el contexto de una fiscalización deberán incluirse en el expediente electrónico ${ }^{16}$ creado para tal efecto.

16 La Ley 21.210 que Moderniza la Legislación Tributaria incorporó en el numeral 8 del artículo 16 de Código Tributario (ст), una referencia específica a la conformación de este expediente señalando que "contendrán el registro electrónico de escritos, documentos, resoluciones, actas de audiencias y actuaciones de toda especie que se presenten o verifiquen en todos los procedimientos administrativos relacionados con la fiscalización y las actuaciones ante el Servicio. Tales antecedentes serán registrados y conservados íntegramente en orden sucesivo 
Cabe tener presente que la incorporación del sistema de expediente electrónico (y, en general, la incorporación de tecnologías de la información) son contestes con los principios de celeridad, economía procesal, no formalización, eficiencia y eficacia, previstos en la Ley 19.880 sobre procedimiento administrativo (LPA) de acuerdo con los pronunciamientos de la Contraloría General de la República (CGR) (Contraloría General de la República, Dictámenes 4941 de 2004, 27953 de 2006, 29845 de 2010, 36764 de 2008 y 68864 de 2011), en la medida que se dé cumplimiento a las disposiciones que regulan los procedimientos respectivos (ver en este sentido también, Circular 40 de 2015).

\section{Fiscalización remota}

Junto con todo lo anterior, cabe señalar que el sir tiene a disposición la facultad de poder fiscalizar remotamente a ciertos contribuyentes, de acuerdo con lo señalado en el artículo 60 bis del CT.

Al respecto y según se señala complementariamente en las instrucciones administrativas (sII, Circular 59, 2015), el sir tiene la facultad de examinar los inventarios, balances, libros de contabilidad, libros auxiliares y documentos del contribuyente, accediendo o conectándose directamente a los sistemas tecnológicos que les sirven de soporte, incluyendo aquellos que permitan la generación de libros o registros auxiliares impresos en hojas sueltas, con el fin de verificar, para fines exclusivamente tributarios, el correcto funcionamiento de dichos sistemas tecnológicos, lo que hará con el objeto de evitar la manipulación o destrucción de datos necesarios para comprobar la correcta determinación de bases imponibles, rebajas, créditos e impuestos.

Esta facultad otorgada a la Administración Tributaria puede aplicarse a los contribuyentes que: i) han sido autorizados para sustituir sus libros de contabilidad o sus registros auxiliares, por hojas sueltas, escritas a mano o en otra forma, o por aplicaciones informáticas o sistemas tecnológicos (art. 17 inc. $4^{\circ}$ del CT); y ii) aquellos respecto de los cuales el sir haya dispuesto la obligatoriedad de reemplazar sus libros de contabilidad o registros auxiliares por sistemas tecnológicos que reflejen claramente su movimiento y el resultado de sus negocios (art. 17 inc. final de CT).

De esta forma, el si puede examinar los inventarios, balances, libros de contabilidad, libros adicionales o auxiliares, documentos y hojas sueltas del contribuyente y de las personas obligadas a retener un impuesto, directamente desde los medios tecnológicos que les sirven de soporte, accediendo o conectándose a dichos sistemas, con lo cual se mejoran y se hacen más expeditas las acciones de revisión y fiscalización. Asimismo, podrá verificar el correcto funcionamiento de dichos sistemas tecnológicos, a fin de evitar la

conforme a su fecha de presentación o verificación a través de cualquier medio que garantice su fidelidad, integridad y reproducción de su contenido". 
manipulación y destrucción de datos necesarios para comprobar la correcta determinación de bases imponibles, rebajas, créditos e impuestos.

\section{Servicios digitales}

El desarrollo de la "economía digital" ha incrementado la capacidad de efectuar transacciones, vender bienes o prestar servicios alrededor del mundo sin la necesidad de tener presencia física en el país donde se encuentra el consumidor (sII, Circular 42, 2020).

\section{A. Legislación vigente}

Con fecha 24 de febrero 2020, se publicó en el Diario Oficial la Ley 21.210 que, dentro de varios cambios a la legislación tributaria, modificó el Decreto Ley 825 de 1974, Ley sobre Impuesto a las Ventas y Servicios (o bien del impuesto al valor agregado, Ley del IVA) que introduce un nuevo hecho gravado especial ${ }^{17}$ aplicable a prestadores de servicios no domiciliados ni residentes en Chile que, desde el extranjero, prestan servicios utilizados en el territorio nacional. La entrada en vigencia de esta modificación legal es a partir del 1 de junio de 2020.

Asimismo, se incorpora a la Ley sobre Impuesto a la Renta (Ley 824, 1974, art. 1), el nuevo artículo 59 bis, que exime de impuesto adicional (IA) los servicios gravados en el nuevo literal $\mathrm{n}$ ) del artículo $8^{\circ}$ de la Ley en los casos que se señalan.

Uno de los objetivos de esta nueva modificación de la Ley del IVA es otorgar un tratamiento adecuado a la economía digital, así como asimilar el tratamiento que enfrentan las actividades digitales con lo aplicado a las empresas tradicionales, a fin de que estén en igualdad de condiciones. La ley señala un sistema simplificado de registro y pago del impuesto en Chile, aplicable a prestadores de servicios no domiciliados ni residentes en el país, conforme al principio de destinación (OECD, 2017, punto 3.1). Para estos es necesario tener presente que se deben distinguir, dos situaciones entre servicios prestados directamente al consumidor final (Business-to-Consumer [B2C], en español, de empresa a consumidor final), o de aquellos prestados a otras empresas (Business-to-Business [B2B], en español, entre empresas).

Este nuevo hecho gravado especial, agregando un literal n) al artículo $8^{\circ}$ de la Ley de IVA se aplica a determinados servicios remunerados realizados por prestadores domiciliados o residentes en el extranjero que sean prestados o utilizados en Chile en forma digital, "utilizados en el territorio nacional", si al tiempo de contratar dichos servicios o realizar los pagos correspondientes a ellos concurren al menos dos de las situaciones que la propia

17 En el artículo $8^{\circ}$, literal n), y un nuevo párrafo $7^{\circ}$ bis al Título II de la Ley del IVA, además de modificar los artícu$\operatorname{los} 3^{\circ}, 5^{\circ}, 11$ y 12 , literal E, numeral 7 , de dicha ley, todos los cuales vienen a regular la tributación y el régimen de administración del IVA. 
norma contempla. De este modo, en cuanto a la territorialidad, el artículo $5^{\circ}$ delimita la aplicación del IVA desde dos perspectivas:

- Desde el punto de vista del prestador del servicio, al señalar que, si la actividad que genera el servicio se realiza en Chile, dicha prestación estará gravada con IVA.

- Desde el punto de vista del usuario, al gravarse con IvA los servicios que se utilicen en el territorio nacional.

Conforme al nuevo inciso tercero del artículo $5^{\circ}$ se presume que el servicio es utilizado en el territorio nacional si concurren, al menos, dos de las siguientes situaciones, como se indicó anteriormente:

- Que la dirección IP del dispositivo utilizado por el usuario u otro mecanismo de geolocalización indiquen que este se encuentra en Chile.

- Que la tarjeta, cuenta corriente bancaria u otro medio de pago utilizado para el pago sea emitida o registrada en Chile.

- Que el domicilio indicado por el usuario para la facturación o la emisión de comprobantes de pago se encuentre ubicado en el territorio nacional.

- Que la tarjeta de módulo de identidad del suscriptor (SIM) del teléfono móvil mediante el cual se recibe el servicio tenga como código de país a Chile.

La presunción de utilización en territorio nacional, referida a los literales a), b), c) y d), solo tiene como propósito reforzar que este nuevo hecho gravado no tiene por finalidad gravar extraterritorialmente y comprende solo a servicios que sean prestados o utilizados en Chile.

Los distintos casos comprendidos por el artículo $8^{\circ}$, literal n) de la Ley del IVA, pueden verificarse tanto en servicios $\mathrm{B} 2 \mathrm{C}$ como $\mathrm{B} 2 \mathrm{~B}$, pero, el mecanismo de declaración y pago es distinto según uno u otro caso. Para efectos de simplicidad, y salvo que deba precisarse algo distinto, se entenderá por:

$\Rightarrow$ Prestador extranjero, plataforma extranjera o desarrollador extranjero u otras expresiones análogas, al prestador, plataforma o desarrollador, según corresponda, domiciliado o residente en el extranjero.

$\Rightarrow$ Prestador chileno, desarrollador chileno, usuario chileno u otras expresiones análogas, al prestador, desarrollador o usuario, según corresponda, domiciliado o residente en Chile.

$\Rightarrow$ Para el caso de "intermediación" de servicios prestados en Chile, cualquiera sea su naturaleza, o de ventas realizadas en Chile o en el extranjero siempre que estas últimas den origen a una importación. 
La primera hipótesis grava con IVA los servicios remunerados de "intermediación" realizados por prestadores domiciliados o residentes en el extranjero y prestados o utilizados en Chile. Dichos servicios, análogos al concepto de corretaje, importan una intermediación asalariada a las partes con el fin de facilitarles la conclusión de sus contratos, cualquiera sea la forma en que dicha intermediación se lleve a cabo, esto es, mediante plataformas digitales u otros medios. A partir de lo anterior, se aclara que los servicios de intermediación prestados por una plataforma extranjera a un prestador extranjero de bienes o servicios están fuera del ámbito de territorialidad de la Ley del IVA. Por tanto, no se grava con IVA la comisión que una plataforma extranjera cobra al desarrollador extranjero de una aplicación que se vende en la plataforma, ni tampoco la comisión que la plataforma extranjera cobra al vendedor extranjero del bien que se importa. Con todo, en ambos casos estarán gravados con IVA tanto la venta de la aplicación utilizada en Chile, como la del bien que se importa al país.

En cambio, si la comisión por la intermediación se cobra a un prestador de servicios (servicio subyacente) chileno, que utiliza el servicio de intermediación en Chile, deberían concurrir las situaciones que describe el inciso tercero del artículo $5^{\circ}$ para presumir la utilización de estos servicios en Chile. Lo mismo se aplicará respecto de la intermediación de bienes prestada a un usuario chileno en la medida que, si los bienes se encuentran en el extranjero, se origine una importación. En el contexto del presente hecho gravado resulta imprescindible distinguir entre:

- El servicio de intermediación, que busca facilitar la celebración de un contrato entre las partes, gravado conforme al numeral 1, literal n) del artículo $8^{\circ}$, y el artículo 3 .

- La operación subyacente (figura 4), que corresponde al contrato que las partes buscan finalmente celebrar y que constituye su principal interés, pudiendo encontrarse gravado, no gravado o exento de IVA conforme a las reglas generales o estar afecto a los impuestos de la Ley sobre Impuesto a la Renta.

Es importante destacar que, al requerir expresamente la ley la existencia de una remuneración cabe aplicar el hecho gravado, cualquiera sea la denominación que ella reciba (como, por ejemplo, cobro por "habilitación de servicio", "tarifa por servicio", "cuota de solicitud" o acceso, cargo, entre otros). Tratándose de plataformas de intermediación que cobran su comisión a los prestadores de servicios o vendedores subyacentes, y esta comisión forma parte del precio cobrado al usuario final, no corresponde recargar el IVA a este usuario final por la comisión cobrada al prestador del servicio subyacente utilizado en Chile o al vendedor subyacente, en la medida que se trate de una comisión gravada. 
Figura 4. Operación SUbyacente

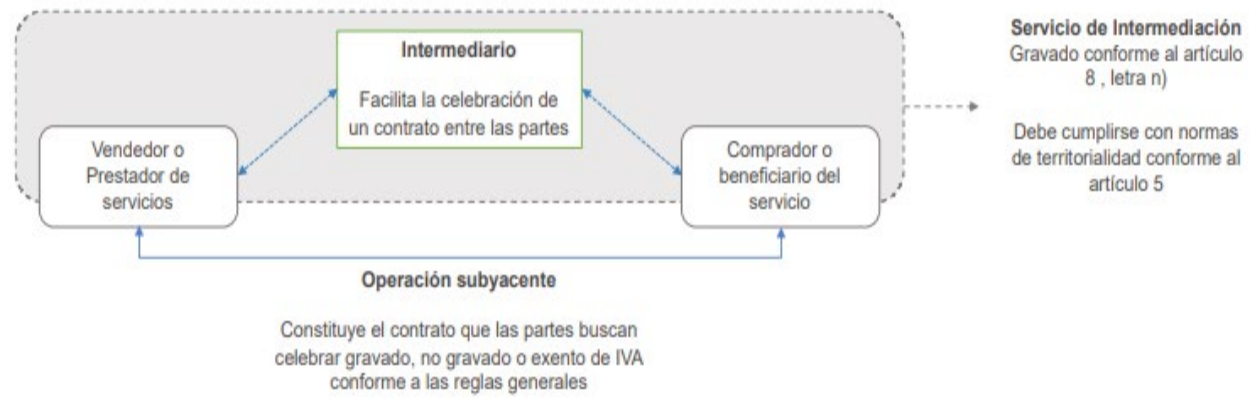

Fuente: elaboración propia.

\section{B. Operaciones objeto de la intermediación gravada}

\section{Los SERVicios PRESTAdos EN ChILE, CUALQUiERA SEA SU NATURALEZA}

La ley grava el servicio de intermediación con independencia del servicio subyacente. En este sentido, la expresión "cualquiera sea su naturaleza" precisa que no es necesario que el servicio subyacente se encuentre gravado con IVA, pudiendo perfectamente tratarse de un servicio no gravado o exento de dicho impuesto. Así, por ejemplo, el servicio subyacente podría encontrarse exento conforme al artículo 12, literal E, numeral 17 de la Ley del IVA, que declara exentos los ingresos en moneda extranjera percibidos por empresas hoteleras y contribuyentes que arrienden inmuebles amoblados registrados ante el sil con motivo de servicios prestados a turistas extranjeros sin domicilio o residencia en Chile (figura 5).

\section{Figura 5. EJEMPlo de SERvicio PRESTAdo}

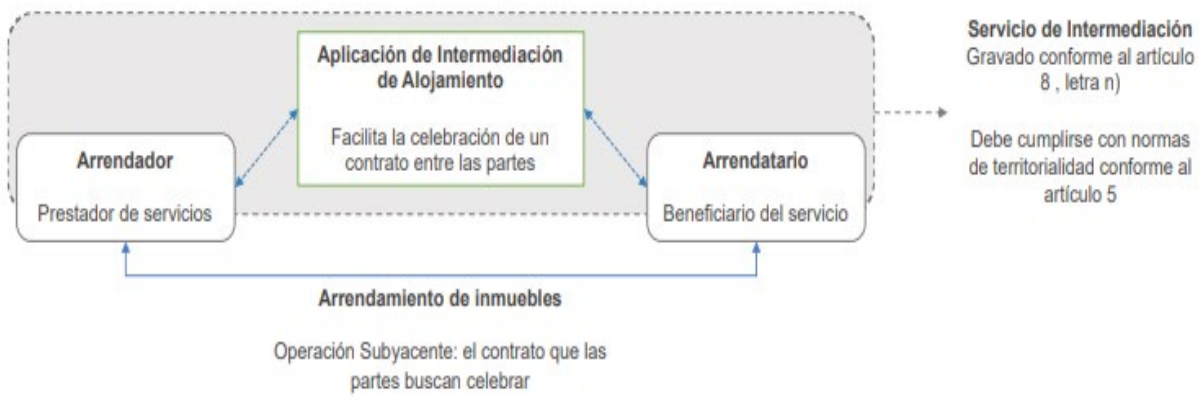

Fuente: elaboración propia. 


\section{LA INTERMEdiación DE VENTAS, YA SEA QUE ESTAS SE REALICEN EN CHILE O EN EL EXTRANJERO, SIEMPRE QUE ESTAS ÚLTIMAS DEN ORIGEN A UNA IMPORTACIÓN}

Esta regulación resulta de la aplicación del principio de destinación según el cual, se atribuye el derecho de imposición al país de destino, es decir, el del lugar donde el bien o servicio se consume, el cual se manifiesta en que se gravan las importaciones en tanto que las exportaciones se declaran exentas ${ }^{18}$.

La figura 6 da cuenta de cómo se aplica esta regla:

\section{Figura 6. LA INTERMEdiación}

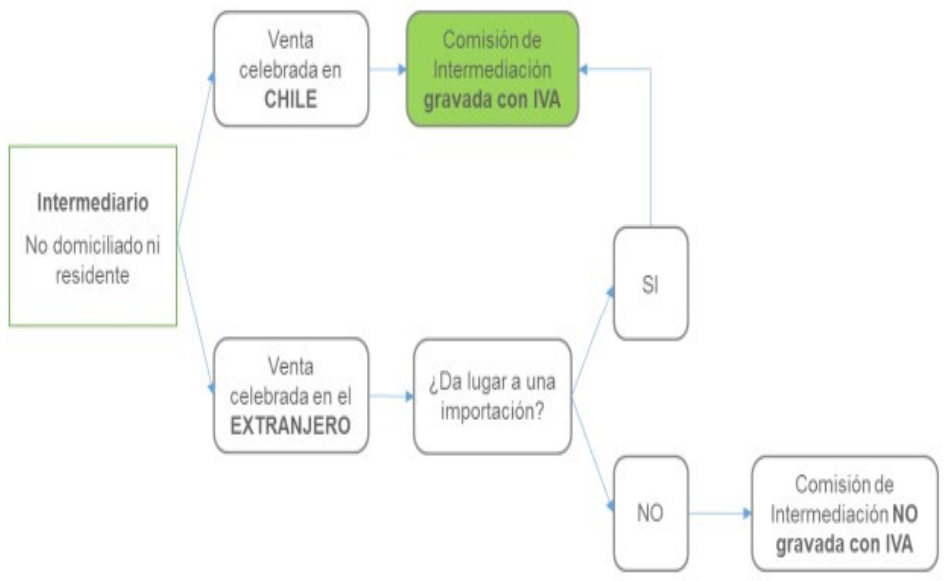

\section{Ejemplo:}

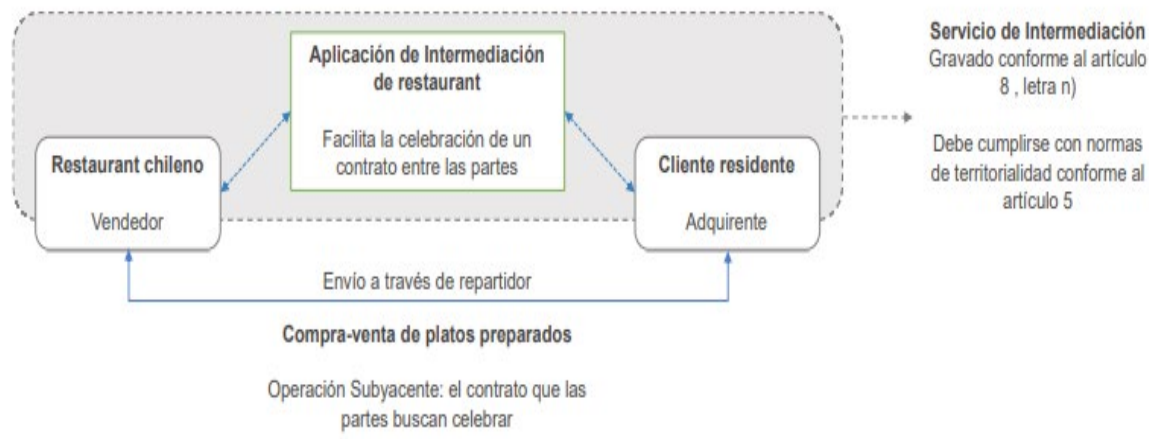

Nota: si el repartidor paga una comisión a la plataforma extranjera, estaría afecta a IVA al configurarse uno de los hechos gravados del artículo 8, literal n) de la Ley de IVA.

Fuente: elaboración propia.

18 Este principio tiene aplicación según se deprende del artículo $8^{\circ}$ literal a) de la Ley del iva que grava las importaciones, y del artículo 12, literal D del mismo texto legal, que exime del IVA a las exportaciones. 
Si se aplicó IVA a la comisión de intermediación de una venta celebrada en el extranjero que, en definitiva, no dio lugar a una importación, el prestador del servicio de intermediación incorporado al régimen simplificado del párrafo $7^{\circ}$ bis del Título II de la Ley del IVA, previa devolución del monto del impuesto a quien lo soportó, podrá aplicar lo dispuesto en el artículo $35 \mathrm{G}$ de dicho cuerpo legal y descontar dicho monto del impuesto por pagar en el periodo tributario correspondiente. Este hecho gravado aplica igualmente tratándose de operaciones B2B, en que el beneficiario de este servicio de intermediación es un contribuyente del impuesto en Chile. Cabe destacar que el prestador del servicio extranjero estará liberado de recargar el IVA correspondiente a esta operación siempre que el beneficiario del servicio le informe que tiene la calidad de contribuyente de IVA. En estos casos, el beneficiario del servicio será el responsable de declarar y enterar el IVA conforme a lo dispuesto en el artículo 11 , literal e) de la Ley de IVA $^{19}$

\section{EL SUMINISTRO O LA ENTREGA DE CONTENIDO DE ENTRETENIMIENTO DIGITAL, TAL COMO VIDEOS, MÚSICA, JUEGOS U OTROS ANÁLOGOS, A TRAVÉS DE DESCARGA, STREAMING U OTRA TECNOLOGÍA, INCLUYENDO PARA ESTOS EFECTOS, TEXTOS, REVISTAS, DIARIOS Y LIBROS}

Este tipo de operación también es conocida como "entretenimiento digital", que se entiende como una forma de satisfacer necesidades de diversión y ocio mediante la combinación entre dispositivos y contenidos digitales. Existe un listado no taxativo en la ley, incluyendo videos, música, juegos u otros análogos. Además, se consideran, por ejemplo, videojuegos, mapping, hologramas, realidad virtual, realidad aumentada, etc.

Cabe tener presente que, conforme a esta segunda hipótesis del literal n), artículo $8^{\circ}$ de la Ley del IVA, se incluyen expresamente como contenidos digitales de entretenimiento a las revistas, los textos, diarios y libros.

En términos generales, los contenidos digitales corresponden a información digitalizada, almacenada en formato electrónico, que se puede copiar, transmitir y utilizar en dispositivos electrónicos, transmitidos mediante redes de telecomunicación, principalmente internet. Por otra parte, la norma señala que el suministro o la entrega de los mencionados contenidos digitales puede hacerse a través de descarga, streaming u otra tecnología. A título meramente ilustrativo, se entiende por descarga la transferencia de archivos informáticos a través de un canal de comunicación para su almacenamiento local y su posterior uso, y, por streaming, la transmisión y uso en tiempo real de datos, o con un leve desfase entre ambas, permitiendo su uso mientras la transmisión aún está en progreso, pudiendo o no almacenarse a largo plazo. Bajo esta segunda hipótesis del literal n) debe aplicarse IVA a la remuneración percibida por los servicios de entretenimiento prestados por medio de plataformas de juegos y apuestas en línea. Sobre el particular, se hace presente que,

19 Para estos efectos, el beneficiario del servicio, que es contribuyente de IVA, deberá emitir una factura de compra por esta operación, a menos que opere alguna exención del IVA. 
conforme se ha señalado (Oficio 122, sII, 2013), la calificación de la licitud o ilegalidad de un determinado juego no le compete al sis, al cual solo le corresponde, dentro de sus atribuciones, determinar si la actividad respectiva se encuentra gravada o no con algún tributo.

\section{Puesta A DisPosición DE SOFTWARE, ALMACENAMIENTO, PLATAFORMAS O INFRAESTRUCTURA INFORMÁTICA}

En la Ley del IVA, en el numeral $3^{\circ}$ del literal $n$ ) del artículo $8^{\circ}$ se grava la puesta a disposición de software, almacenamiento, plataformas o infraestructura informática en forma remunerada por prestadores domiciliados o residentes en el extranjero. Este hecho gravado comprende, en lo principal, distintos modelos de operación de la llamada "computación en nube" o cloud computing, tales como software as a service (SaaS), platform as a service (PaaS) e infraestructure as a service (IaaS), la cual, en términos generales, implica la provisión de los señalados recursos informáticos a través de internet. A falta de definición legal en nuestro ordenamiento jurídico, es posible recurrir a lo indicado por otros organismos técnicos. Al respecto, por ejemplo, de acuerdo con el Instituto Nacional de Estándares y Tecnología, dependiente del Departamento de Comercio de Estados Unidos, la computación en la nube es un modelo que permite el acceso en todas partes, de una manera conveniente y bajo demanda, a un grupo compartido de recursos informáticos configurables (por ejemplo, redes, servidores, almacenamiento, aplicaciones y servicios) que se pueden aprovisionar y liberar rápidamente con un mínimo esfuerzo de gestión o interacción del proveedor de servicios (Badger et al., 2012).

Este modelo de nube se compone de los siguientes tres modelos de servicio:

- Software como servicio (SaaS). El consumidor puede utilizar las aplicaciones del prestador que se ejecutan en una infraestructura en la nube. Se puede acceder a las aplicaciones desde varios dispositivos de clientes a través de una interfaz de cliente ligero, como un navegador web (por ejemplo, correo electrónico basado en la web) o una interfaz de programa. El consumidor no gestiona ni controla la infraestructura de la nube subyacente, incluida la red, los servidores, los sistemas operativos, el almacenamiento o incluso las capacidades de las aplicaciones individuales, con la posible excepción de la configuración de la aplicación limitada específica del usuario.

- Plataforma como servicio (PaaS). El consumidor puede implementar en la infraestructura de la nube aplicaciones creadas o adquiridas por él, usando lenguajes de programación, bibliotecas, servicios y herramientas compatibles con el prestador. El consumidor no administra ni controla la infraestructura de nube subyacente, incluida la red, servidores, sistemas operativos o almacenamiento, pero tiene control sobre las aplicaciones implementadas y posiblemente los ajustes de configuración para el entorno de alojamiento de aplicaciones. 
- Infraestructura como servicio (IaaS). El servicio entregado al consumidor es el aprovisionamiento de procesamiento, almacenamiento, redes y otros recursos informáticos fundamentales donde el consumidor puede implementar y ejecutar softwares, que puede incluir sistemas operativos y aplicaciones. El consumidor no administra ni controla la infraestructura de nube subyacente, pero tiene control sobre los sistemas operativos, el almacenamiento y las aplicaciones implementadas; y posiblemente un control limitado de componentes de red seleccionados (por ejemplo, firewalls de host).

- Publicidad, con independencia del soporte o medio a través del cual sea entregada, materializada o ejecutada finalmente, el numeral 4 , literal n) del artículo $8^{\circ}$ de la Ley del IVA grava con dicho impuesto a los servicios remunerados de publicidad realizados por prestadores domiciliados o residentes en el extranjero. Aclara la Ley que la forma en la cual sea entregada, materializada o ejecutada la publicidad (por ejemplo, por medios digitales o tradicionales) no es una condicionante para la aplicación del impuesto.

- Devengo del impuesto. De acuerdo con el artículo $9^{\circ}$, literal a) de la Ley del IVA, la regla general respecto del devengo es que el impuesto que grava las prestaciones de servicios se devengará en la fecha en que la remuneración se perciba o se ponga, en cualquier forma, a disposición del prestador del servicio, en caso de que no se hubieren emitido facturas o boletas, según corresponda, o no correspondiere emitirlas. Se calculará aplicando "a dicha contraprestación" la tasa establecida en el artículo 14 de la Ley del IVA con una tasa del 19\%, sobre la base de la suma de los impuestos "recargados", por los servicios prestados en el periodo tributario respectivo. Para estos efectos, se entiende por "periodo tributario", un tiempo de uno o tres meses seguidos, a elección del contribuyente, debiendo declarar y pagar los impuestos devengados en un periodo tributario, hasta el día 20 del primer mes siguiente; es aplicable la regla general de devengo, es decir, el impuesto se devenga en la fecha en que la remuneración se percibe o se pone, en cualquier forma, a disposición del prestador del servicio, a pesar de que la prestación se verifique en una oportunidad distinta al pago o puesta a disposición de la remuneración. El devengo del impuesto se materializará al momento de producirse el recargo de la remuneración en la tarjeta de pago con provisión de fondos, débito, crédito o cualquier otro sistema de pago que haya designado el usuario.

- Sujeto responsable del pago del impuesto. El artículo $10^{\circ}$, inciso segundo de la Ley del IVA, dispone que el impuesto afectará a quien realice la prestación en aquellas operaciones definidas como servicios o que la ley equipare a tales. En estos casos, la tasa correspondiente deberá aplicarse al total del precio cobrado, según lo dispuesto en al artículo 15 de la Ley del IVA que dispone que la base imponible del IVA corresponde al valor de la operación respectiva. Al respecto, cabe señalar que, de acuerdo con el artículo 28 del Código Tributario, el gestor de una asociación o de cuentas en participación y de cualquier encargo fiduciario será responsable exclusivo del cumplimiento de las obligaciones tributarias referentes a las operaciones que constituyan el giro de la asociación u objeto del encargo. Lo anterior es aplicable al caso de una plataforma o 
marketplace ${ }^{20}$ que aparece como prestador del servicio subyacente y recauda, por sí o a través de un tercero, el total del precio correspondiente a dicho servicio por cuenta del prestador subyacente. En consecuencia, y sin perjuicio de la posibilidad de ordenarse el cambio de sujeto del impuesto en casos particulares, para los efectos tributarios será la plataforma o marketplace el sujeto responsable de retener, declarar y pagar el impuesto, cualquiera sea la naturaleza del encargo fiduciario que exista con el prestador del servicio subyacente, así como la modalidad en que se recauden los pagos (por sí o a través de terceros).

Por otra parte, la ley modificó el artículo 11 de la Ley del IVA, disponiendo que el beneficiario del servicio será considerado sujeto del impuesto cuando se cumplan los siguientes dos requisitos:

- Que la prestación sea realizada por un prestador domiciliado o residente en el extranjero.

- Que el beneficiario del servicio sea un contribuyente del Título II de la Ley del IVA.

En consecuencia, en caso de configurarse estos dos requisitos, el beneficiario del servicio tiene la obligación de informar al prestador extranjero que no debe efectuar la retención del IVA. El incumplimiento de la referida obligación o la entrega de información falsa no será imputable al prestador extranjero quien, además, no tendrá la obligación de verificar la calidad de contribuyente del IVA (o no) que le informe su cliente nacional, sin perjuicio de tener que enviar periódicamente al sil la nómina de los contribuyentes a quienes no se les haya efectuado la retención del impuesto en razón de la información recibida.

Reglas de armonización entre IVA e IA en relación con los hechos gravados del artículo $8^{\circ}$, literal n) de la Ley del IVA. A continuación, y sin perjuicio de las instrucciones que se impartan en otras circulares, se comentan los aspectos más relevantes y ciertos casos, a modo referencial, que permiten interpretar de manera sistemática el propósito y alcance de las modificaciones legales.

- Modificación al artículo 12, literal E, numeral 7 de la Ley del IVA: previo a la modificación introducida a este artículo, la exención del IVA allí contenida favorecía a los ingresos afectos al impuesto establecido en el artículo 59 de la LIR, salvo que estos remuneraran servicios prestados en Chile y dichos ingresos gozaran de una exención del referido IA por aplicación de leyes o de convenios para evitar la doble tributación en el país. La modificación en comento incorporó también en dicha excepción a los servicios utilizados en Chile. Por tanto, desde la entrada en vigencia de esta modificación, no procederá aplicar la liberación de IVA contenida en el artículo 12, literal E), numeral 7 de la Ley del IVA, tratándose

20 Los marketplaces o e-marketplaces son plataformas online creadas y gestionadas por una empresa que actúa como un tercero neutral para poner en contacto a compradores y vendedores de bienes y servicios con el objeto de que estos efectúen una transacción comercial. 
de las sumas que remuneran servicios prestados o utilizados en Chile que se encuentren exentas del IA contenido en el artículo 59 de la LIR en virtud de una ley o de un convenio. $\mathrm{Si}$, por el contrario, dichas sumas no se favorecen con una exención del mencionado IA, resultará plenamente aplicable la exención del IVA.

En resumen, con esta modificación, aquellos servicios prestados o utilizados en Chile, que se encuentren afectos a IVA y cuya remuneración se encuentre afecta también al IA del artículo 59 de la LIR, solo pagarán en virtud del artículo 12, literal E), numeral 7, uno de los dos tributos, en este caso, el IA. Como se aprecia, la modificación introducida se enmarca en el contexto más general de modificaciones necesarias para armonizar la introducción del nuevo hecho gravado establecido en la literal n) del artículo $8^{\circ}$ de la Ley del IVA con, a su turno, el IA del artículo 59 de la LIR.

Exención del IA por ciertos pagos al extranjero establecida en el literal F) del artículo 14 de la LIR: de acuerdo con el artículo 14, literal F), de la LIR, los pagos realizados por empresas sujetas a lo establecido en el artículo 14 literal A) o D) del mismo cuerpo legal cuyo promedio anual de ingresos de su giro no exceda de 100.000 unidades de fomento en los tres años comerciales anteriores a aquel en que se realiza el pago respectivo, por la prestación de servicios de publicidad en el extranjero y el uso y la suscripción de plataformas de servicios tecnológicos de internet, a contribuyentes no domiciliados ni residentes en Chile, estarán exentos del IA establecido en el c 2 del artículo 59. Conforme lo anterior, y por aplicación de la contraexcepción dispuesta en el artículo 12, literal E), numeral 7 de la Ley del IVA, en la medida que los pagos efectuados por las empresas referidas en el párrafo anterior respecto de servicios prestados o utilizados en Chile se encuentren exentos del IA del artículo 59 de la LIR, esos pagos quedarán afectos a IVA.

Nueva exención de IA: la ley agregó un nuevo artículo 59 bis a la LIR, el cual establece que los servicios a que se refiere el artículo $8^{\circ}$, literal n) de la Ley del IVA, estarán exentos del IA, en tanto ellos se presten a personas naturales que no sean contribuyentes de IVA. El objetivo de la exención en comento es, por una parte, asegurar la aplicación del IVA a los servicios gravados en el nuevo literal n) del artículo $8^{\circ}$ de la Ley del IVA, prestados por contribuyentes no domiciliados ni residentes en Chile, en tanto hace inaplicable la excepción contenida en el artículo 12, literal E, numeral 7 de la Ley del IVA; y por la otra, evitar que ambos impuestos (IVA e IA) se apliquen simultáneamente al mismo servicio. La exención en comento, en conjunto con el establecimiento de un régimen simplificado aplicable a los respectivos prestadores de servicios no domiciliados ni residentes en Chile, permite simplificar el cumplimiento de las obligaciones tributarias, particularmente la declaración y el pago del IVA con que se afectan los servicios que se prestan a personas naturales que no sean contribuyentes del referido impuesto. Finalmente, cabe hacer presente que los servicios del artículo $8^{\circ}$, literal n) de la Ley del IVA prestados por contribuyentes no domiciliados ni residentes en Chile a personas jurídicas no se benefician con la exención de IA establecida en el artículo 59 bis de la LIR. Asimismo, no se benefician con dicha exención de IA los servicios prestados por contribuyentes no domiciliados ni residentes en Chile a personas naturales que sean contribuyentes de IVA. Por consiguiente, la aplicación de IA 
o de IVA se sujetará a las normas generales en la materia y a lo dispuesto en el artículo 12, literal E, numeral 7 de la Ley del IVA.

A partir de lo dispuesto en los artículos $8^{\circ}$, literal n), y 12, literal E, numeral 7 de la Ley del IVA, así como del artículo 59 bis de la LIR, se realiza el siguiente un resumen tomado de las comunicaciones dadas por las autoridades tributarias (figura 7) ${ }^{21}$ :

Figura 7. LEY DEL IVA ${ }^{22}$

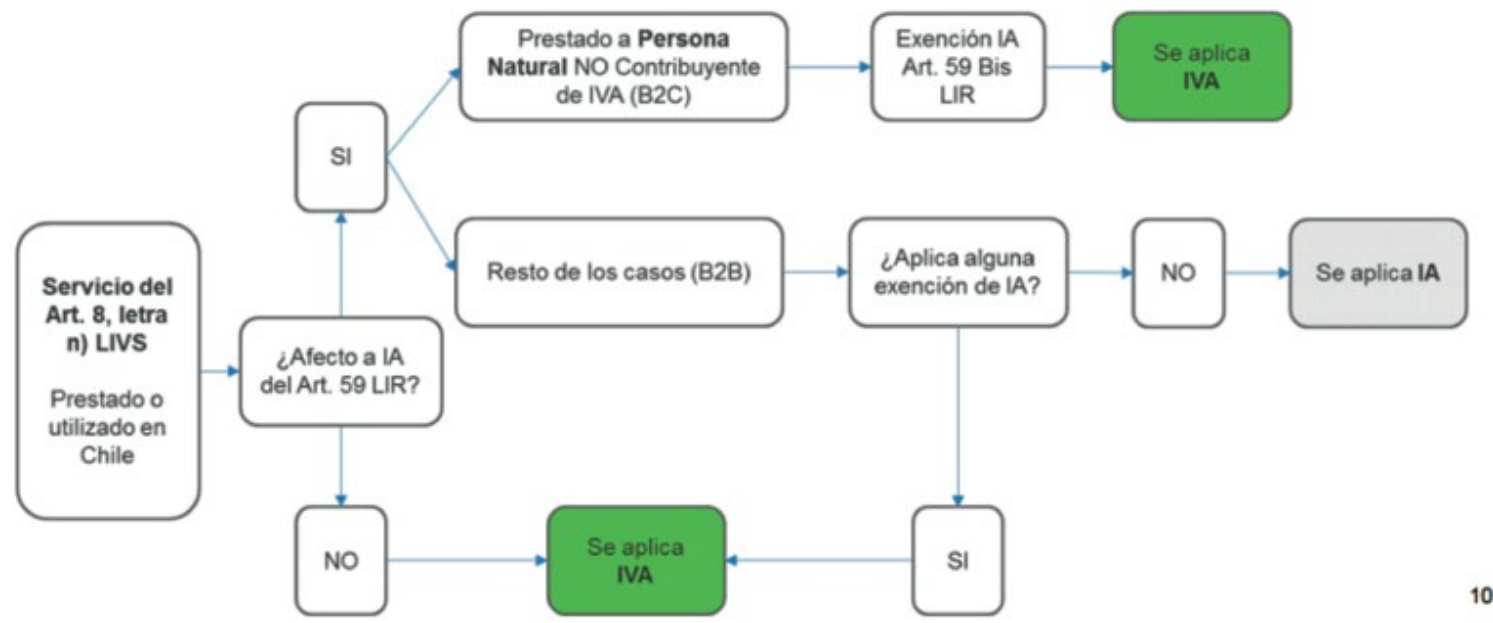

Fuente: Ley del IVA, artículos $8^{\circ}$, literal n), y 12, literal E, numeral 7.

5. Algunas Situaciones ESPECIALES DEL ARTíCULO $8^{\circ}$, LITERAL N) DE LA LEY DEL IVA, FRENTE AL IA

\subsection{Intermediación de servicios prestados en Chile}

EI artículo 59, inciso cuarto, numeral 2 de la LIR, grava con IA, con tasa de $35 \%$, entre otros conceptos, las remuneraciones por servicios prestados en el extranjero, dentro de los cuales cabe incluir en principio los servicios de intermediación gravados conforme al numeral 1 del literal n) del artículo $8^{\circ}$ de la Ley del IVA. Lo anterior, sin perjuicio de la tasa aplicable conforme a los convenios para evitar la doble tributación. Con todo, el artículo 59, inciso cuarto, numeral 2 de la LIR dispone que estarán exentas de IA, entre otras sumas, las pagadas por concepto de "comisiones", incluyendo tanto el mandato comercial como la correduría.

21 Siempre que corresponda conforme a la aplicación del principio de territorialidad.

22 En el cuadro resumen, la expresión "no afecto a IA del art. 59 LIR", por simplicidad, quiere significar que el pago está afecto, pero que en definitiva no aplica por operar una exención conforme a la ley o los convenios. 


\subsection{Suministro o entrega de contenido de entretenimiento digital}

i. Juegos: de acuerdo con lo señalado por el sII, la prestación que involucra la provisión de videojuegos que permite jugar con o a través del programa por un prestador sin domicilio ni residencia en Chile, consiste en un servicio de entretención y esparcimiento enmarcado en el numeral 2 del artículo 59 de la LIR (SII, Oficio 2000, 2017), gravándose con IA a tasa de $35 \%$ o bien la tasa correspondiente conforme a los convenios para evitar la doble tributación eventualmente aplicables. Lo anterior, por cierto, sin perjuicio de que, conforme al artículo 59 bis de la LIR, estos pagos puedan estar exentos del IA tratándose de servicios prestados a personas naturales que no sean contribuyentes de IVA.

ii. Videos, películas, música, textos, revistas, diarios y libros: cabe entender que, cuando se descargan dichos productos vía internet, se está en presencia de una licencia de uso, en virtud de la cual quien tiene la titularidad del derecho de autor, sea por sí mismo o como cesionario de aquel, otorga la autorización para descargar dichos elementos en el equipo del usuario final. En este contexto, se enmarcaría dentro de lo dispuesto en el artículo 59 de la LIR, gravándose con IA a tasa de $30 \%$, sin perjuicio de lo establecido en los convenios vigentes para evitar la doble tributación.

iii. Puesta a disposición de software, almacenamiento, plataformas o infraestructura informática: el artículo 59 de la LIR grava con IA las cantidades pagadas o abonadas en cuenta por el uso, goce o explotación de modelos de programas computacionales que no sean calificados como estándar. Esta puesta a disposición también quedaría gravada en el numeral 3 del literal $n$ ) del artículo $8^{\circ}$ de la Ley de IVA. Esto no significa que tenga un doble gravamen, pues debe determinarse, en cada caso, si procede la aplicación de la exención establecida en el artículo 12, literal E, numeral 7 de la Ley del IVA, o aquella exención establecida en el artículo 59 bis de la LIR.

iv. Tratándose de cantidades pagadas o abonadas en cuenta a personas sin domicilio ni residencia en Chile, por el uso, goce o explotación de programas estándar, estas se encuentran exentas del IA establecido en el artículo 59 de la LIR, pero gravadas con IVA como consecuencia de la modificación incorporada por la ley al artículo 12, literal E, numeral 7 de la Ley del IVA, que incluyó como contraexcepción a la exención de IVA establecida en este numeral, a los servicios que gozan de exención de IA por aplicación de leyes o convenios para evitar la doble imposición, que se presten o utilicen en Chile.

v. Publicidad: el artículo 59, inciso cuarto, numeral 2 de la LIR grava con IA, a tasa de $35 \%$, las remuneraciones por servicios prestados en el extranjero (dentro de los cuales se incluyen los servicios de publicidad gravados por el numeral 4 , literal n), artículo $8^{\circ}$ de la Ley del IVA). Lo anterior sin perjuicio de la tasa correspondiente conforme a los convenios para evitar la doble tributación eventualmente aplicables. El párrafo segundo del numeral 2 del inciso cuarto del artículo 59 de la LIR declara exentas de IA las sumas pagadas en el caso de bienes y servicios exportables, por publicidad y promoción, entre otros. Para que proceda esta exención los servicios deben guardar 
estricta relación con la exportación de bienes y servicios producidos en el país y los pagos correspondientes, considerarse razonables a juicio del siI, debiendo para este efecto los contribuyentes comunicarlos, en la forma y plazo que fije el director del sII. Con todo, respecto de las sumas pagadas en el caso de bienes y servicios exportables, por publicidad y promoción, entre otros conceptos, se debe tener presente lo señalado en el literal a), anterior, a propósito de las comisiones (no gravadas con IA ni tampoco con IVA del literal n) del artículo $8^{\circ}$ de la Ley del IVA).

Además, existirá un régimen simplificado para contribuyentes no domiciliados ni residentes en Chile basado en el trabajo realizado por la Organización para la Cooperación y el Desarrollo Económicos (OCDE), y otras organizaciones internacionales, así como la experiencia individual de ciertos países, indican que una adecuada recaudación de IVA en operaciones transfronterizas B2C se logra exigiendo a los prestadores su registro y el pago del impuesto en el país donde tiene lugar el consumo. En la implementación de tal sistema, se recomienda a las jurisdicciones considerar el establecimiento de un régimen de registro y cumplimiento simplificado, a efectos de facilitar el cumplimiento por parte de los prestadores de servicio no residentes. En concordancia con las recomendaciones de la OCDE, la Ley incorpora al Título II de la Ley del IVA un nuevo párrafo $7^{\circ}$ bis, que establece un régimen simplificado para contribuyentes no domiciliados ni residentes en Chile.

\section{Régimen simple}

\section{A. Principales aspectos del régimen simplificado}

Siguiendo las recomendaciones de la OCDE (OECD, Mechanisms for the effective collection of VAT/GST when the supplier is not located in the jurisdiction of taxation, punto C.1.1 15, 2017), se facilita el cumplimiento de las obligaciones impuestas a los prestadores extranjeros, liberando a los contribuyentes del presente régimen de las siguientes cargas o disposiciones de la Ley del IVA:

"Los contribuyentes sujetos al presente régimen no tendrán derecho a crédito fiscal" (art. 35 C). Dicha disposición acerca al presente régimen a los denominados "regímenes de solo pago" (pay-only regimes), buscando asegurar un adecuado balance entre la simplificación y el resguardo de la recaudación fiscal, toda vez que el contribuyente extranjero se beneficiará de una declaración de impuestos menos compleja, facilitando dicho proceso y la labor fiscalizadora de este Servicio. Sin embargo, se hace presente que los proveedores de servicios prestados desde el extranjero tienen derecho a registrase y tributar de acuerdo al régimen general que rige a los contribuyentes en el país. Lo anterior significa que podrán obtener el rol único tributario, podrán realizar un inicio de actividades y podrán tener derecho a un crédito contra el débito fiscal determinado en el periodo respectivo. 
Liberación de la obligación de emitir documentos tributarios por sus operaciones (art. 35 C). En virtud de la norma referida, los contribuyentes incorporados al presente régimen se encuentran liberados de la obligación de emitir boletas, facturas, notas de crédito o débito y otros documentos tributarios.

No será aplicable lo dispuesto en el Párrafo $3^{\circ}$ del Título IV de la Ley del IVA (art. 35 $\mathrm{H})$, que regula el denominado "Registro de Compras y Ventas", atendido que los contribuyentes del presente régimen no emiten documentos tributarios ni efectúan adquisiciones de bienes o servicios con derecho a crédito fiscal.

En general, no serán aplicables las demás disposiciones de la Ley del IVA en lo que no sean compatibles con la naturaleza del presente régimen simplificado (art. $35 \mathrm{H}$ ).

Principalmente, y a modo meramente referencial, cabe señalar:

- Artículo 20, relativo al débito fiscal y determinación del impuesto a pagar;

- Artículo 21, rebajas del impuesto determinado o débito fiscal;

- Artículo 22, facturación indebida;

- Párrafo $6^{\circ}$ del Título II (artículos 23 a 28), del crédito físcal;

- Párrafo $2^{\circ}$ del Título IV (artículos 52 a 58), de las facturas y otros comprobantes de ventas y servicios;

- Artículo 64, sobre declaración y pago del impuesto, entre otros.

\section{B. Inscripción}

El procedimiento de inscripción, y el ejercicio de la facultad contenida en el nuevo artículo 35 B, que se analiza a continuación, se definirá por medio de una resolución dictada al efecto. La inscripción no implica en caso alguno la constitución de un establecimiento permanente en Chile, conforme se establece en los artículos 2 numeral 12, 38 y 58 numeral 1 de la LIR, ni genera más obligaciones que las que expresamente se imponen en la ley y en las instrucciones dictadas al efecto. El listado de los contribuyentes extranjeros que cumplen con sus obligaciones tributarias mediante su inscripción en el presente régimen será publicado en el sitio web del sII.

\section{Cálculo, declaración y pago del impuesto}

La ley dispone que, para estos efectos, se entenderá por "periodo tributario" un lapso de uno o tres meses seguidos, a elección del contribuyente, teniendo presente que el primer periodo a declarar y pagar corresponde al mes de junio del año 2020. De manera excepcional y únicamente por este primer periodo, los contribuyentes podrán declarar y pagar los impuestos correspondientes a dicho mes, adicionándolo al tercer trimestre fijo, correspondiente a los meses de julio, agosto y septiembre, que deben ser enterados hasta el 20 de octubre de 2020. De este modo, los prestadores extranjeros que ejerzan esta opción 
deberán realizar su primera declaración y pago de este IVA en octubre, por los servicios gravados que presten durante los meses de junio, julio, agosto y septiembre.

La declaración y el pago del impuesto se realizará electrónicamente, a través del portal o mecanismo digital que el sII habilitará al efecto, en las siguientes fechas:

\begin{tabular}{|l|l|}
\hline Trimestre & Meses \\
\hline 1 & Enero, Febrero y Marzo \\
\hline 2 & Abril, Mayo y Junio \\
\hline 3 & Julio, Agosto y Septiembre \\
\hline 4 & Octubre, Noviembre y Diciembre \\
\hline
\end{tabular}

\section{Covid-19 y precios de transferencia}

El problema de la crisis global sanitaria provocada por el covid-19 ha sido transversal a todos los países de la región, por lo que hemos diseñado un trabajo que contempla un resumen de las problemáticas que pueden llegar a ocurrir y algunas soluciones dependiendo de los criterios y ajustes que apliquen las empresas y soluciones de lineamientos de la OCDE y de las autoridades fiscales.

Es innegable que la pandemia ha impactado directamente la salud de las personas, así como al core bussiness (negocio principal) de las empresas, con las incertidumbres de contratación y continuidad laboral, con presupuestos preparados en el 2019 y de años anteriores para el año 2020, sin contemplar esta grave crisis real de la economía, muy diferente a la crisis del año 2008, también conocida como crisis subprime ${ }^{23}$, cuyo origen fue de carácter financiero. La crisis producida por el covid-19 puede ser ya considerada como una de las perores junto con la recesión económica de los años treinta, o como las crisis en épocas de Guerra Mundial.

Esta crisis ha generado una serie de eventos que impactan directamente en las empresas con extraordinarias disminuciones de las ventas en la mayoría de los sectores económicos, mercados, industrias y empresas pequeñas, medianas y grandes, especialmente del sector transporte, turismo y otros. Asimismo, como mencionamos, existen otras industrias que han tenido ingresos sorprendentes o "anormales", que están en la línea de los insumos, materiales, equipos e infraestructura del ámbito de la salud.

Estamos en presencia de una crisis que ha implicado el cierre temporal de locales, la paralización de actividades productivas, despidos de personal, entre otros gastos o costos impensados en cualquier presupuesto de una empresa. Esto ha generado un alto grado de incertidumbre, una descoordinación y una muy necesaria actividad de recopilación de información, respaldando en este momento todo lo posible para poder explicar la relación

23 Crisis del aumento en los préstamos hipotecarios otorgados a personas sin historial crediticio, llamadas hipotecas de alto riesgo o subprime, fenómeno alentado por las políticas públicas, que genera una burbuja. 
del impacto del covid-19 en las empresas. Un ejemplo de esto son las nuevas propuestas o pronósticos de ventas, costos adicionales, compra de activos intangibles, licencias y portátiles para poder desarrollar el teletrabajo, paralización de actividades por procesos de cuarentenas dictada por leyes de los Estados, o bien producto del proceso mismo de la cadena de suministro de bienes y servicios dentro del grupo empresarial, anulación o suspensión de órdenes de compras y ventas, entre otros aspectos.

Todo lo anterior ha generado una gran incertidumbre en el comportamiento de las rentabilidades de las empresas, industrias y mercados dentro de un rango normal, y la búsqueda de empresas comparables ante una situación totalmente afectada por la economía global que provoca una serie de dudas sobre la aplicación de políticas en las empresas, cambios o reorganizaciones estructurales o funcionales de la gestión y el cumplimiento tributario y las medidas o los criterios especiales de las autoridades fiscales. Especialmente dentro de situaciones que plantean un problema serio en cada revisión y documentación fiscal en esta materia.

De esta manera, se han determinado una serie de problemas y algunos puntos relevantes que se deberán considerar por parte de las empresas y de las autoridades tributarias, y probablemente de una actualización o modificación de los lineamientos en precios de transferencias de la OCDE o de la ONU, ante una crisis global económica de gran dimensión, que incluye una seria recesión económica y futura reactivación de las economías de países desarrollados y emergentes que tendrán una particularidad de reacondicionamiento y reorganización de funciones empresariales, que provocarán diferencias entre los países de estas características.

Este trabajo solo contempla un resumen de las problemáticas que pueden llegar a ocurrir, y algunas o pocas soluciones dependiendo de los lineamientos de la oCDE y de las autoridades fiscales.

\section{A. Problemas en materia de precios de transferencia}

Hemos diseñado una serie de problemas y soluciones potenciales en materia de precios de transferencia con base en criterios, lineamientos de la OCDE y de la situación particular de cada industria que impacta la operación del negocio y el desempeño financiero del grupo empresarial.

\section{AdAPTACiÓn O AJUSTES DE LA POLÍticA DE PRECIOS DE TRANSFERENCIA}

Las políticas de Precios de Transferencia existentes antes de la presente crisis fueron diseñadas considerando circunstancias normales de mercado. Hoy es muy probable que haya cambios en las funciones, los activos y riesgos. Nuevas redefiniciones, tanto en las metodologías como en otros tipos de ajustes no habituales o bajo circunstancias anormales de mercados. Ajustes secundarios, o bien en los resultados de las empresas para poder documentar fehacientemente las rentabilidades y búsqueda de empresas comparables. 
Lo mismo ocurre con respecto a las problemáticas específicas que pueden ser consideradas para la revelación de criterios o lineamientos que potencialmente deben adoptarse con base en la legislación local, acuerdos multilaterales o bien con los lineamientos de precios de transferencia de la OCDE y la ONU.

Igualmente, en aquellos grupos económicos que se basan en las filiales que operan bajo riesgos limitados, en una situación de crisis global de la economía como la generada por el covid-19, en una industria en que la disminución de las ventas puede generar un deterioro que no permitirá cubrir sus costos fijos estructurales ni otros costos adicionales como despidos, indemnizaciones por términos anticipados de contratos, pérdidas de inventarios entre otros costos.

Lo anterior afecta directamente la operación de compra y venta de bienes o servicios, que se torna insuficiente para remunerar estas actividades, lo que implica un beneficio operativo que cae a niveles tendientes a cero o negativos y genera una compleja estructura de costos sostenible. Esto está sucediendo especialmente con empresas que han tenido que cerrar sucursales o tiendas en regiones que han sido muy golpeadas por la crisis.

Por otro lado, pueden existir medidas externas desde el Estado o bien internas por decisiones de la administración de las empresas, que son medidas extraordinarias de ajustes puntuales o temporales a los precios de transferencia, compensaciones de costos, reestructuraciones empresariales o funcionales, de personal, gastos de investigación y desarrollo, de marketing, de transformación digital como, por ejemplo, ventas en línea a consumidores finales B2C, o nuevas plataformas digitales, distribución o logística, que pudiesen generar algún tipo de reconversión como, por ejemplo, subcontratación de transporte (Uber, Rapid, o personal contratado) para acercar los bienes y servicios a los clientes, a fin de generar niveles de beneficio operativo por debajo de valores normales de mercado, con estrategias que permiten seguir cubriendo sus costos variables, sin la necesidad de cerrar sus negocios.

Además, en el caso de otras operaciones intragrupos se podrán producir los ajustes y otros tipos de flujos que generalmente se han aplicados como, por ejemplo:

Gastos de management fees, royalties, know how, licencias, asesorías técnicas, u otro tipo de gastos intragrupo, considerando que podrían generar un mayor gasto o para la situación financiera de las entidades del grupo. En consecuencia, será posible que se realicen ajustes en las políticas considerando temas muy importantes como:

- La temporalidad del ajuste: cuánto tiempo será necesario, un año, dos años o hasta que dure el proceso de la crisis covid-19.

- La amplitud del ajuste: debemos aplicar a todas las filiales, empresas, industrias, o se deben distinguir o diferenciar por sus resultados.

- La gradualidad del ajuste: ¿qué grado de ajuste deberemos aplicar, medio, alto, bajo o definitivamente dejar de aplicar algún gasto?

- El periodo de comparabilidad: ¿qué periodos debemos considerar, 10 o 20 años o periodos o años de crisis financiera? ¿Periodos iniciales de empresas durante tres a cinco años, que tengan pérdidas? ¿Periodos de crisis globales económicos y de guerras globales? 
La políticas de financiamiento en las que algunos Estados han expedido leyes o bien solicitando a los bancos e instituciones financieras créditos blandos con tasas cercanas o tendientes a cero para reactivar a las empresas y generar liquidez, pueden ser consideradas beneficios para empresas del grupo; sin embargo, si no califican crediticiamente, los préstamos intragrupo tendrán que evaluar permanente el costo financiero, tasa de intereses, plazo de créditos y oportunidades para no tener problemas en la comparabilidad de gastos financieros deducibles a tasas "normales" o ajustadas por la crisis del covid-19.

La revisión de los análisis económicos desarrollados para valorar las transacciones intragrupo o elementos como el análisis funcional y de riesgos, las cláusulas contractuales intragrupo que pudieran regular circunstancias de imposibilidad de cumplimiento por fuerza mayor u otras cláusulas (ejemplo stop loss), las alternativas realistas para las partes y la capacidad financiera de las mismas de asumir estas pérdidas manteniendo el equilibrio económico de las relaciones intragrupo.

En aquellas situaciones en que se aplican los métodos de distribución del beneficio o profit Split, que se basan en la contribución relativa o el valor agregado en el reparto de los beneficios de un negocio a las diferentes compañías, la gran problemática es la situación de pérdidas agregadas y, en este caso, se debe replantear si procede o no esta distribución en las diferentes compañías. ¿Cuál será el criterio de distribución o aplicación? ¿Existirán límites en la aplicación por parte de las autoridades locales?

\section{ACUERDO ANTICIPADO DE PRECIOS (APA)}

En el caso de que existan las políticas o los cuerdos anticipados de precios con las administraciones tributarias, hay que tener presente si hay cláusulas especiales ya pactadas, evaluar la posibilidad de comunicar a las administraciones tributarias el desahucio del Acuerdo por externalidades provocadas por covid-19, o bien explorar la posibilidad de renegociar ${ }^{24} \mathrm{el}$ acuerdo con un ajuste propuesto según las condiciones aplicables al mismo indicando la gradualidad y temporalidad, entre otros aspectos.

Sin perjuicio de lo anterior, todas estas situaciones planteadas podrían afectar tanto a las empresas multinacionales con matriz en los Estados de residencia como las operaciones en el exterior a través de sus filiales o empresas relacionadas. En este sentido, es muy relevante tener presentes todos estos casos que de una forma u otra puedan afectar positiva o negativamente a la realidad de cada grupo multinacional.

De acuerdo con lo anterior, es necesario tener preparada toda la documentación de respaldo y las razones para justificar los ajustes que harían las partes independientes en situaciones similares para ser presentadas ante las autoridades fiscales.

En aquellos casos que, como producto de la crisis covid-19 se ha generado un impacto significativo en la forma de organizar la cadena de valor de un negocio podría ser

24 Esto depende exclusivamente de la legislación local vigente en un APA, o bien en un Acuerdo Multilateral de Precios (MAPA), en las condiciones pactadas por los Estados. 
necesaria una revisión más profunda de la operativa intragrupo y el modelo de precios de transferencia ante la nueva realidad. Ante esta situación se podría anticipar que no sea suficiente un ajuste temporal a la política de precios, por el contrario, se requiera de una modificación que se adapte de manera adecuada a la reestructuración de las operaciones y al nuevo esquema de supply chain de los negocios.

De esta forma, en la nueva normalidad tras el covid-19 se podría requerir el cierre de operaciones en diferentes países o el replanteamiento de países productores para evitar dependencias de un determinado proveedor y acercar la producción a los mercados.

\section{CRITERIOS, CAMBios de LEGISLACión O NUEVOS LiNEAMIENTOS DE LAS AUTORIDADES FISCALES Y DE LA OCDE}

En esta situación tan particular en que nos encontramos como consecuencia de la crisis provocada por el covid-19 en Latinoamérica debemos estar muy atentos y preparados para la documentación y el respaldo de todo tipo de ajustes por realizar, revisión del análisis funcional ante cambios o reestructuraciones de los riesgos asociados y de activos, que pueden generar cambios relevantes en los ajustes de comparabilidad y en el periodo o años por considerar para los efectos de la comparabilidad, épocas de crisis económicas, pandemias, guerras globales. Por otro lado, los criterios ante eventuales inspecciones fiscales que, como podemos anticipar, verificarán la razonabilidad del impacto económico de esta crisis en la base imponible de las compañías y buscarán comparar el resultado del modelo de remuneración en términos de base imponible posreestructuración con el que había en la situación anterior al cambio de modelo. Esto, sin duda, generará cuestionamientos, ajustes y disputas en materia de precios de transferencias.

De acuerdo con lo anterior, tenemos que profundizar en las recientes publicaciones de las Directrices de la OCDE en materia de precios de transferencia en operaciones financieras y otros servicios intragrupo; sin embargo, resulta casi evidente la necesidad de asegurar o generar al menos un cierto grado de certeza dentro de tanta incertidumbre, estar atentos a las recomendaciones que efectúen las autoridades tributarias y la ocDE, quizás con una nueva directriz para casos de crisis global de la economía, mediante la propuesta de soluciones a las problemáticas que hemos planteado y otras que puedan surgir en esta dinámica de crisis debida a la pandemia.

\section{Conclusiones}

Si bien podemos asegurar que el sil no debió cambiar enteramente su forma de funcionar producto de la crisis sanitaria, ya que contaba con grandes avances en materia informática que le permitían realizar una gran cantidad de trámites y gestiones de manera virtual, cabe señalar que la implementación de algunas medidas no ha estado exenta de complicaciones, puesto que muchas solicitudes efectuadas de manera remota necesitan la concurrencia personal para obtener cierta documentación necesaria (como la obtención de 
formularios en papel para ser enviados por correo electrónico) o simplemente no cuentan con un formulario digital disponible para realizar la solicitud.

A partir de la reformas tributarias incorporadas a nuestro ordenamiento, Leyes 20.780 de 2014 y 20.899 de 2016 y, posteriormente, con la modernización tributaria de la Ley 21.210 de 2020, se ha potenciado significativamente la digitalización de las relaciones con el contribuyente, con la finalidad de hacer las gestiones ante el si de forma más expedita, ágil y oportuna, facilitando los deberes de gestión y fiscalización que debe cumplir la autoridad tributaria.

El contexto actual del covid-19 ha puesto a prueba las modificaciones y adecuaciones legislativas anteriormente señaladas. Al respecto, si bien se ha logrado agilizar los trámites administrativos de cumplimiento y entrega de información, aún la digitalización no se ha implementado completamente y existen situaciones en el contexto de control y procedimientos de fiscalización efectivas.

En el sentido anteriormente expuesto, el director nacional de sir, Fernando Barraza, ha señalado en la Cuenta Pública de la institución, que durante este tiempo se buscará implementar un "sistema integrado de atención al contribuyente", con el cual se desarrollarán nuevas estrategias de fiscalización a distancia.

Por tanto, a nivel país nos encontramos en un proceso de prueba de las facultades digitales de la autoridad tributaria actualmente vigentes. A su vez, se esperen con expectación los nuevos programas de fiscalización remota que informe dicha autoridad y cómo estos pueden afectar las pretensiones y los derechos de los contribuyentes.

Es ahí donde se deben abocar los esfuerzos del sir en sistematizar y actualizar las plataformas de atención virtual para permitir que todas las gestiones puedan ser realizadas de manera remota, dejando para una gestión presencial solo aquellas que sean eminentemente necesarias o que por su naturaleza no puedan efectuarse de otra forma.

Chile, al igual que otros países del mundo, ha debido enfrentar en un breve plazo las consecuencias tanto sanitarias como económicas de la pandemia producida por el covid-19. En el ámbito de la economía, las medidas de índole tributaria han jugado un papel central, ya que permiten inyectar liquidez a las empresas y, al mismo tiempo, evitar trámites que en esta situación son difíciles de cumplir.

En este sentido, Chile, al igual que otras legislaciones, ha tomado medidas de aplazamiento o diferimiento de la declaración y el pago de algunos impuestos, tales como el impuesto a las ventas y servicios (IVA), o los pagos provisionales mensuales.

Al mismo tiempo, se han fortalecido las herramientas informáticas que la autoridad tributaria ha puesto a disposición de los contribuyentes, como una forma de evitar que estos concurran a las oficinas del sir. Existe, en consecuencia, una gran cantidad de actuaciones que los contribuyentes pueden efectuar a través del sitio web de la autoridad tributaria, por medio de aplicaciones en los teléfonos móviles y por correo electrónico. Lo anterior significará, probablemente, el despegue de algunas herramientas contempladas en nuestra legislación y que hasta el momento tenían una aplicación más limitada como, por ejemplo, el expediente electrónico. 
En la misma línea, existen diversas declaraciones juradas cuyo plazo de envío al sir fue pospuesto, todo con la idea de facilitar el cumplimiento tributario y considerando que hay muchas empresas que han debido cerrar de manera obligatoria.

Respecto al pago de los impuestos, el organismo encargado de la cobranza de los impuestos -Tesorería General de la República- ha implementado convenios más flexibles y otras facilidades para los contribuyentes con dificultades para enfrentar sus compromisos.

Todas estas medidas implicarán, desde luego, una disminución de la recaudación fiscal de una magnitud que en la actualidad no es posible de cuantificar. Por lo anterior, es probable que en un mediano plazo la discusión tributaria sobre la carga impositiva vuelva a abrirse.

\section{Referencias}

Badger, L., Grance, T., Patt-Corner, R. y Voas, J. (2012). Cloud Computing Synopsis and Recommendations (Special Publication 800-146). https://nvlpubs.nist.gov/nistpubs/Legacy/SP/nistspecialpublication800-146.pdf

Dirección de Presupuestos del Ministerio de Hacienda (2020, 15 de abril ). Informe de finanzas públicas. http://www.dipres.cl/598/articles-201476_Informe_PDF.pdf

Servicio de Impuestos Internos (2020, 2 de abril). Más de 660 mil contribuyentes ya realizaron su Declaración de Renta, un 48,7\% más que el año pasado a igual fecha. http://www.sii.cl/noticias/2020/020420noti01er.htm

\section{Jurisprudencia}

Biblioteca del Congreso Nacional de Chile (2014). Ley 20.780.

Biblioteca del Congreso Nacional de Chile (2016). Ley 20.899.

Biblioteca del Congreso Nacional de Chile (2020). Ley 21.210.

Biblioteca del Congreso Nacional de Chile (2020). Ley 21.217.

Biblioteca del Congreso Nacional de Chile (2020). Ley 21.225.

Comisión del Mercado Financiero (2020). Norma de Carácter General 435.

Congreso Nacional de Chile (28 de abril de 2020). Boletín 13487-05.

Contraloría General de la República de Chile (2004). Dictamen 4941. 
Contraloría General de la República de Chile (2006). Dictamen 27953.

Contraloría General de la República de Chile (2010). Dictamen 29845.

Contraloría General de la República de Chile (2008). Dictamen 36764.

Contraloría General de la República de Chile (2011). Dictamen 68864.

Ministerio de Hacienda de Chile (2020). Decreto Supremo 420.

Ministerio de Hacienda de Chile (1974). Ley sobre Impuesto a la Renta. [Ley 824 de 1974].

OECD (2017). International VAT/GST Guidelines.

OECD (2017). Mechanisms for the effective collection of VAT/GST when the supplier is not located in the jurisdiction of taxation.

Servicio de Impuestos Internos (2013). Oficio 122.

Servicio de Impuestos Internos (2015). Circular 40.

Servicio de Impuestos Internos (2015). Circular 59.

Servicio de Impuestos Internos (2017). Oficio 2000.

Servicio de Impuestos Internos (2020). Circular 32.

Servicio de Impuestos Internos (2020). Circular 42.

Fecha de recepción: 24 de junio de 2020

Fecha de aprobación par 1: 01 de julio de 2020

Fecha de aprobación par 2: 16 de julio de 2020 